\title{
RECENT ADVANCEMENTS IN RUBBER NANOCOMPOSITES
}

\author{
Maurizio Galimberti,,${ }^{1} *$ Valeria Cipolletti,${ }^{1}$ SARa Musto, ${ }^{1}$ Serena Cioppa,,${ }^{1}$ Giulia Peli, ${ }^{1}$ Marco \\ Mauro, ${ }^{2}$ Guerra Gaetano, ${ }^{2}$ Silvia Agnelli, ${ }^{3}$ Riccò Theonis, ${ }^{3}$ Vineet Kumar ${ }^{4}$ \\ ${ }^{1}$ Politecnico di Milano, Department of Chemistry, Materials and Chemical Engineering “G. Natta," Via \\ MANCINELLI 7, 20131 Milano, ITALY \\ ${ }^{2}$ UNIVERSITÀ DEGLI STUdi di SALERNO, VIA GIOVANNI PAOLO II 132, 84084 FisCIANO, SALERNO, ITALY \\ ${ }^{3}$ UNIVERSITÀ DEGLI STUDI DI BRESCIA, VIA BRANZE 38, 25123 BRESCIA, ITALY

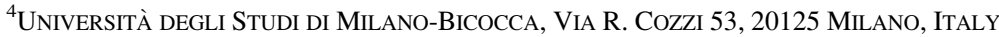

RUBBER CHEMISTRY AND TECHNOLOGY, Vol. 87, No. 3, pp. 417-442 (2014)

\begin{abstract}
Nanocomposites were prepared via melt blending, based on organically modified clays (OC), carbon nanotubes (CNT), and graphitic nanofillers made by a few layers of graphene (nanoG). In particular, nanocomposites based on a hybrid filler system, with a nanostructured filler such as carbon black (CB), are examined. It is shown that low crystalline order in the interlayer space of a layered nanofiller (such as OC and nanoG) leads to easier delamination. Nanofillers give rise to filler networking at low concentration, particularly in the presence of CB. Hybrid filler systems lead to nanocomposites' having initial moduli that are much higher than those calculated through the sum of the initial modulus of composites containing either only CB or only the nanofiller. Nanofillers enhance the matrix modulus by a multiplication factor that depends only on the nanofiller type and content, regardless of whether the matrix is a neat or a CB-filled polymer. Furthermore, the fillerpolymer interfacial area is shown to be a parameter able to correlate the mechanical behavior of both nano-CNT and nanostructured (CB) fillers. By plotting values of the composite initial modulus versus the filler-polymer interfacial area, points due to CB, CNT, and the hybrid CB-CNT system lie on the same curve. [doi:10.5254/rct.14.86919]
\end{abstract}

\section{INTRODUCTION}

Over the past decades, the rubber world has been characterized by the appearance of so-called nanofillers, ${ }^{1,2}$ which means fillers whose primary particles have at least one dimension below 100 nanometers ${ }^{3}$ and that can be individually dispersed in the rubber matrix. Three main families of nanofillers have achieved large interest, both in the academic and industrial laboratories, and have found commercial applications: clays and organoclays (OC), ${ }^{1,2,4-9}$ carbon nanotubes (CNT), ${ }^{1,2,10}$ and graphene or graphitic nanofillers made with a few layers of graphene (named as graphite nanoplatelets [GNP], nanosheets, or nanoflakes). In particular, rubber nanocomposites (RCN) based on graphitic nanofillers constitute one of the hottest topics in worldwide research. ${ }^{1-26}$

These nanofillers are already used in rubber composites for demanding dynamic mechanical applications, such as in tire compounds. As shown in Figure 1, tire compounds with nanofillers are designed to have improved dynamic-mechanical properties and better barrier effect, which are expected to lead to reduced rolling resistance, better dry handling, and higher durability and reduced weight. Moreover, better thermal and electrical properties are expected.

However, improved performances can be achieved only if OC, CNT, and nanographite are really nanofillers, that is, if they are really dispersed as individual particles in the polymer matrix.

This contribution to the 184th ACS Rubber Division Meeting is focused on the main aspects that steer the behavior of RCN. We present an overview of recent advancements arising from our research on the following items:

(i) Structure of nanofillers and nanocomposites.

Ways to achieve the even dispersion of individual nanofiller particles in particular are discussed. 


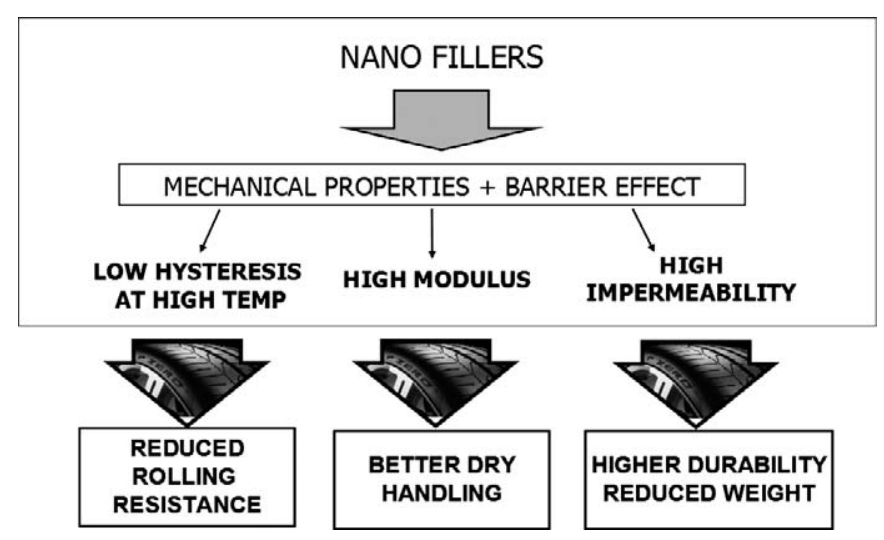

FIG. 1. - Improved properties and performances of tire compounds thanks to nanofillers.

(ii) Filler networking

(iii) Dynamic and quasi-static mechanical behavior at medium and large strain

As nanofillers are discussed as ingredients suitable for application in tire compounds, hybrid filler systems, made of nanofillers and so-called nanostructured fillers such as carbon black (CB) and silica, have to be considered. This article is focused on hybrid nanocomposites with $\mathrm{CB}$ as the nanostructurd filler, prepared via melt blending.

Organoclays discussed in this article are based on montmorillonite (Mt) as the clay mineral. The selected grade of nanographite, named as nanoG, has a high shape anisotropy, ${ }^{14,27}$ which means a high ratio between the crystallites dimensions in direction parallel and orthogonal to structural layers, and CNT are multiwalled. Common features among nanofillers are highlighted. The structure of nanofillers and nanocomposites was studied by means of X-ray diffraction (XRD) and transmission electron microscopy (TEM) analysis. Quasi-static and dynamic-mechanical measurements were performed on un-cross-linked and cross-linked composites.

\section{EXPERIMENTAL}

\section{MATERIALS}

Clays and OC. - The Mt sample was Dellite ${ }^{\circledR}$ HPS from Laviosa Chimica Mineraria S.p.A. (Livorno, Italy), with cation exchange capacity equal to $128 \mathrm{mEq} / 100 \mathrm{~g}$. The OC sample was Dellite $67 \mathrm{G}$ from Laviosa Chimica Mineraria S.p.A., with $2 \mathrm{HT}$ as the compensation cation. The weight $\%$ of Mt and of the ammonium moiety were 55 and 45, respectively.

Carbon Fillers. - The multiwalled CNTs were Baytubes C150 P from Bayer Material Science, with a chemical purity of $95 \%$ by weight, a length in the $1-10 \mathrm{~mm}$ range, a number of walls between 3 and 15, and outer and inner diameters of 10-16 nm and $4 \mathrm{~nm}$, respectively. They were used as received, without any treatment. The Brunauer-Emmett-Teller (BET) surface area was measured to be $199.9 \mathrm{~m}^{2} / \mathrm{g}$, and the di-isobutyl phthalate (DBP) absorption number was measured to be $316.3 \mathrm{~mL} / 100 \mathrm{~g}$.

NanoG was Synthetic Graphite $8427^{\circledR}$ from Asbury Graphite Mills Inc. (Asbury, NJ, USA), with $99.5 \%$ carbon content. The BET surface area was measured to be $330 \mathrm{~m}^{2} / \mathrm{g}$, and the DBP absorption number was measured to be $162.4 \mathrm{~mL} / 100 \mathrm{~g}$. 
Carbon Black N326 (CB) was from Cabot (Billerica, MA, USA), with $30 \mathrm{~nm}$ as the mean diameter of spherical primary particles. The BET surface area was $77 \mathrm{~m}^{2} / \mathrm{g}$, and the DBP absorption number was $85 \mathrm{~mL} / 100 \mathrm{~g}$.

Rubber. - Synthetic poly(1,4-cis-isoprene) (IR) (Nizhnekamskneftekhim Export, Nizhnekamsk, Russian Federation) had trade name SKI3 and 70 Mooney Units as Mooney viscosity $\left(\mathrm{M}_{\mathrm{L}}(1\right.$ $\left.+4) 100{ }^{\circ} \mathrm{C}\right)$.

Compounds' Ingredients. - The following ingredients were used as received: bis(3triethoxysilylpropyl) tetrasulfide (Si 69; Evonik, Pandino, Italy), ZnO (Zincol Ossidi, Monza, Italy), stearic acid (Sogis, Cremona, Italy), N-(1,3-dimetilbutil)-N'-fenil-p-fenilendiammina (6PPD) (Crompton, Middlebury, CT, USA), sulfur (Solfotecnica, Ravenna, Italy), N-cyclohexylbenzothiazol-2-sulfenamide (CBS) (Flexsys, Kingsport, TN, USA), N-cyclohexylthiophthalimide (premature vulcanization inhibitor, PVI) (Flexsys), and phtalic anhydride (Aldrich, Milano, Italy).

Peroxide for Nanocomposite Cross-linking. - Dicumylperoxide was from Arkema (Colombes, France), with a concentration of $40 \%$ by weight.

\section{PREPARATION OF OC AT THE SOLID STATE}

The preparation of OC at the solid state was performed as reported in refs 28 and 29.

The reaction of OC with $\mathrm{ZnO}$ was carried out as follows. Ten grams of OC containing $2 \mathrm{HT}$ as the compensating cation and stearic acid as further guest ( $2 \mathrm{HT}$ : stearic acid $=1: 1$ as molar ratio) were mixed with $\mathrm{ZnO}$ in a $250-\mathrm{mL}$ round-bottomed flask. The molar amount of $\mathrm{ZnO}$ was equal to the molar amount of stearic acid. The flask was kept at $100{ }^{\circ} \mathrm{C}$ for $1 \mathrm{~h}$. The final powder was discharged and characterized through XRD analysis.

\section{MILLING OF OC}

Mt/2HT was milled in a centrifugal ball mill S100 from Retsch (Haan, Germany), in a grinding jar with a volume of $250 \mathrm{~mL}$. About $10 \mathrm{~g}$ of OC was put in the jar, which was allowed to rotate at 440 rpm for $4 \mathrm{~h}$.

\section{NANOCOMPOSITE PREPARATION FROM MELT BLENDING}

A Brabender ${ }^{\circledR}$ type internal mixer with $50 \mathrm{~mL}$ mixing chamber was used for the preparation of nanocomposites. The following standard procedure was adopted for the preparation of nanocomposites, whose formulations are reported in Tables I-VII. The rubber was introduced into the mixer at $80^{\circ} \mathrm{C}$ and masticated for $1 \mathrm{~min}$. The filler was added, and mixing was carried out for $5 \mathrm{~min}$. The master batch was discharged at a temperature in a range from $110^{\circ} \mathrm{C}$ to $115^{\circ} \mathrm{C}$ and fed again to the mixer after $16 \mathrm{~h}$, leaving it in the mixer at $60^{\circ} \mathrm{C}$ and $30 \mathrm{rpm}$ for $1 \mathrm{~min}$. Peroxide was then added, and mixing was performed for a further $2 \mathrm{~min}$. Compounds were finally homogenized by passing them five times on a two-roll mill operating at $50{ }^{\circ} \mathrm{C}$, with the front roll rotating at $30 \mathrm{rpm}$ and the back roll at $38 \mathrm{rpm}$, and with $1 \mathrm{~cm}$ as the nip between the rolls.

\section{CROSS-LINKING}

The cross-linking reaction was performed at $150{ }^{\circ} \mathrm{C}$ for $20 \mathrm{~min}$. MDR rheometric analysis was conducted using a Monsanto MDR rheometer, carrying out the test for $20 \mathrm{~min}$ at $150{ }^{\circ} \mathrm{C}$, an oscillation frequency of $1.66 \mathrm{~Hz}$ (100 oscillations per minute), and an oscillation amplitude of $\pm 0.5^{\circ}$. Nanocomposites were observed to achieve a plateau value for $\mathrm{M}_{\mathrm{H}}$ without any reversion. 
TABLE I

FORMULATIONS OF IR-BASED COMPOSITES WITH CB AND OC AS FILLERS ${ }^{a}$

\begin{tabular}{lccc}
\hline & \multicolumn{3}{c}{ Composite } \\
\cline { 2 - 4 } Ingredient & 1 & 2 & 3 \\
\hline IR & 100 & 100 & 100 \\
CB & 60 & 50 & 50 \\
Intercalated OC & 0 & 8.3 & 0 \\
Delaminated OC & 0 & 0 & 8.3 \\
Sylane TESPT & 0.8 & 0.8 & 0.8 \\
\hline
\end{tabular}

${ }^{a}$ Intercalated organoclay: Dellite 67G. Amount of ingredients are indicated in phr. Other ingredients: $\mathrm{ZnO} 4$, stearic acid 2, 6PPD 2, sulfur 2 , DCBS 1.8, phtalic anhydride 1 , PVI 0.3 .

\section{CHARACTERIZATION OF CARBON FILLERS, OC, AND COMPOSITE SURFACE AREA AND DBP ABSORPTION}

The BET surface area was determined with the ASTM D6556 method. The DBP absorption number was measured with the ASTM D2414 method.

\section{ANALYSIS}

Wide-angle X-ray diffraction (WAXD) patterns were taken with an automatic Bruker D8 Advance diffractometer, in reflection, with nickel-filtered $\mathrm{Cu}-\mathrm{K} \alpha$ radiation $(1.5418 \AA$ ), at $35 \mathrm{KV}$ and $40 \mathrm{~mA}$. The captions of the figures indicate if the intensities of the WAXD pattern were corrected for polarization and Lorentz factors. Corrections were done to have the right comparison between low and high $2 \theta$ angle reflections. Correction was not introduced to allow a better visibility of the $(00 \ell)$ peaks. $d$-spacings were calculated using Bragg's law. The $D_{h k \ell}$ correlation length of the nanofillers' crystals was determined by applying the Scherrer equation (Eq. 1):

$$
D_{h k \ell}=K \lambda /\left(\beta_{h k \ell} \cos \theta_{h k \ell}\right)
$$

where $K$ is the Scherrer constant, $\lambda$ is the wavelength of the irradiating beam $(1.5419 \AA$, CuK $\alpha)$, $\beta_{h k \ell}$ is the width at half height, and $\theta_{h k \ell}$ is the diffraction angle. The introduction of a correction factor has to be used in case $\beta_{h k \ell}$ is lower than $1^{\circ}$.

TABLE II

FORMULATIONS OF IR-BASED COMPOSITES WITH EITHER CB OR CNT AS

FILLERS $^{a}$

\begin{tabular}{lrrrccc}
\hline & \multicolumn{5}{c}{ Composite } \\
\cline { 2 - 7 } Ingredient & 1 & 2 & 3 & 4 & 5 & 6 \\
\hline IR & 100 & 100 & 100 & 100 & 100 & 100 \\
Filler & 0 & 2.5 & 5.0 & 10.0 & 20.0 & 30.0
\end{tabular}

${ }^{a}$ Amount of ingredients expressed in phr. Other ingredient: DCUP $1.4 \mathrm{phr}$. 
TABLE III

FORMULATIONS OF IR-BASED COMPOSITES WITH NANOG AS FILLER ${ }^{a}$

\begin{tabular}{lrrrccc}
\hline Ingredient & 1 & 2 & 3 & 4 & 5 & 6 \\
\hline IR & 100 & 100 & 100 & 100 & 100 & 100 \\
NanoG & 0 & 2.8 & 5.6 & 11.1 & 22.2 & 33.3 \\
\hline
\end{tabular}

${ }^{a}$ Amount of ingredients expressed in phr. Other ingredient: DCUP $1.4 \mathrm{phr}$.

\section{CHARACTERIZATION OF NANOCOMPOSITES}

TENSILE TESTS

Tensile tests were performed according to Standard ISO 37:2011.

DYNAMIC-MECHANICAL TESTS

Tests on Un-cross-linked Compounds of Table I. - Tests were performed by using the apparatus reported in ref 45.

Strain Sweep Test. - Samples were kept in the instrument, at the smallest strain amplitude (1 $\mu \mathrm{m}=0.1 \%$ ), for $330 \mathrm{~min}$, to have equilibrated conditions of mechanical properties. The strain sweep test was then performed, with $0.1 \%-30 \%$ as the strain amplitude range and a frequency of 1 $\mathrm{Hz}$.

Determination of the Master Curve. - Master curves were obtained by performing multifrequency $(0.3,1,3,10,30 \mathrm{~Hz})$ tests at $0.1 \%$ as strain amplitude and by increasing the temperature from -50 to $100{ }^{\circ} \mathrm{C}$. Collected data were elaborated by TA Instruments Rheology Advantage Data Analysis software, in accordance with the principle of time-temperature superposition. The temperature of $-45{ }^{\circ} \mathrm{C}$ was chosen as the reference temperature for the translation of experimental points along the frequency axis.

Tests on Peroxide Cross-linked Compounds (Formulations Are in Table I-Table VII). — Tests were performed with a Monsanto R.P.A. 2000 rheometer in the torsion mode. A first strain sweep (0.1-25\% shear strain amplitude) was performed at $50{ }^{\circ} \mathrm{C}$ and $1 \mathrm{~Hz}$, then the sample was kept in the instrument at the minimum strain amplitude $\left(\gamma_{\min }=0.1 \%\right)$ for $10 \mathrm{~min}$, to achieve equilibrated conditions. Dynamic tests were finally performed at $50^{\circ} \mathrm{C}$ at increasing strain amplitude $(0.1-25 \%$ shear strain amplitude) with a frequency of $1 \mathrm{~Hz}$.

TABLE IV

FORMULATIONS OF IR-BASED COMPOSITES WITH CB AND CNT AS FILLERS ${ }^{a}$

\begin{tabular}{lrrrrrr}
\hline & \multicolumn{6}{c}{ Composite } \\
\cline { 2 - 7 } Ingredient & 1 & 2 & 3 & 4 & 5 & 6 \\
\hline IR & 100 & 100 & 100 & 100 & 100 & 100 \\
CB & 0 & 1.25 & 2.50 & 5.00 & 10.00 & 15.00 \\
CNT & 0 & 1.25 & 2.50 & 5.00 & 10.00 & 15.00 \\
\hline
\end{tabular}

${ }^{a}$ Amount of ingredients are expressed in phr. Other ingredient: DCUP 1.4 phr. 
TABLE V

FORMULATIONS OF IR-BASED COMPOSITES WITH CB AND NANOG AS FILLERS $^{a}$

\begin{tabular}{lrrrrrc}
\hline & \multicolumn{6}{c}{ Composite } \\
\cline { 2 - 7 } Ingredient & 1 & 2 & 3 & 4 & 5 & 6 \\
\hline IR & 100 & 100 & 100 & 100 & 100 & 100 \\
CB & 0 & 1.25 & 2.50 & 5.00 & 10.00 & 15.00 \\
NanoG & 0 & 1.39 & 2.78 & 5.56 & 11.11 & 16.67 \\
\hline${ }^{a}$ Amount of ingredients expressed in phr. Other ingredient: DCUP 1.4 phr.
\end{tabular}

\section{RESULTS AND DISCUSSION}

PART I: STRUCTURE OF NANOFILLERS AND NANOCOMPOSITES

Layered Nanofillers for RCN. - Nanofillers such as clay, OC, CNT, and nanoG have two main common features: they have a high aspect ratio and they are layered. Figure 2a shows the structure of Mt, most used clay for RCN preparation, made of stacked tetrahedral octahedral tetrahedral layers with a regular van der Waals gap containing alkaline and alkali-earth cations. ${ }^{30}$ To have the clay compatible with the polymer matrix, the organic modification is performed with organophilic ammonium salts. ${ }^{31}$ The alkyl chains located at the interface with the polymer matrix promote the clay polymer compatibilization. The alkyl chains' arrangement in the interlayer space depends on layer charge and alkyl chains number and length. Figure $2 b$ represents a clay modified with a dialkylammonium with long hydrocarbon tails, which are known to give paraffin-type arrangements with different tilting angles. Figure $2 \mathrm{c}$ shows the graphite crystal structure that is maintained when few layers of graphene are stacked to give nanoG (or GNP) or are wrapped to give CNT.

The XRD analysis is used to investigate the organization of such layered fillers, in their pristine state and in the polymer matrix. Figure 3 shows the XRD pattern of Mt (Figure 3a) and of Mt modified with dimethylditalloylammonium (2HT; Figure $3 b$ ).

As already reported, ${ }^{4,5}$ the introduction of the ammonium cation in the interlayer space leads to the expansion of the $\mathrm{d}_{001}$ basal spacing and, in the case of $2 \mathrm{HT}$ as the ammonium cation, to a high degree of order, as revealed by the presence of some $(00 \ell)$ reflections. ${ }^{32,33}$ Figure 4 shows the XRD patterns of the carbon fillers formed by layers of $\mathrm{sp}^{2}$-bonded carbon atoms: CB (Figure 4a), CNT (Figure 4b), and nanoG (Figure 4c), to confirm what was reported above on the presence of the identical crystalline repeating unit in the three carbon allotropes, which are, however, endowed with different degrees of order.

By using the Scherrer equation (see the Experimental section), it is possible to calculate the correlation length of the crystalline domain in the direction orthogonal to structural layers. Taking into account the interlayer distance, it is then possible to estimate the number of stacked layers. Values for the nanofillers, in their pristine state, are shown in Table VIII.

TABLE VI

FORMULATIONS OF IR-BASED COMPOSITES WITH DIFFERENT FILLERS ${ }^{a}$

\begin{tabular}{lccc}
\hline Ingredient & IR & Filler & DCUP \\
\hline phr & 100 & 12 & 1.4 \\
\hline
\end{tabular}

${ }^{a}$ Fillers $=$ OC, CNT, graphene, CB. 
TABLE VII

FORMULATIONS OF IR-BASED COMPOSITES WITH CB AND DIFFERENT FILLERS $^{a}$

\begin{tabular}{lcccc}
\hline Ingredient & IR & CB & Filler & DCUP \\
\hline phr & 100 & 60 & 12 & 1.4 \\
\hline
\end{tabular}

${ }^{a}$ Filler $=\mathrm{OC}, \mathrm{CNT}$, graphene, $\mathrm{CB}$.

Distribution and Dispersion of Nanofillers in RCN. - To achieve ultimate RCN properties, it is widely acknowledged that individual layers or tubes have to be evenly dispersed in the polymer matrix. CNT, nanoG, and OC can be efficiently distributed in hydrocarbon polymer matrices, thanks to their easy compatibilization. As mentioned above, to have such compatibilization in the case of OC, the hydrocarbon tails of the ammonium cation have to be located at the interface with the polymer matrix. In fact, the progressive extraction of the ammonium cation from $\mathrm{OC}^{29}$ leads to an increasingly difficult dispersion of the clay in hydrocarbon polymer matrices. The dispersion of $\mathrm{OC}$ is improved by enhancing the number and the length of the hydrocarbon tails. ${ }^{33}$ Analogously, the modification of CNT, with a long hydrocarbon substituent ${ }^{2}$ or a sylane such as bis(3triethoxysilylpropyl) tetrasulfide, ${ }^{34}$ improves distribution and dispersion in the polymer matrix, promoting CNT debundling and reducing tubes breaking due to the mixing stress. As discussed below, oxidation and successive reduction or modification help the dispersion of nanographites, ${ }^{18,21,22}$ promoting their exfoliation.

It appears that to achieve the ultimate dispersion of nanofillers as individual layers in the polymer matrix, particularly when nanocomposites are prepared via melt blending, the current state of the art proposes their chemical modification. In the following, the effect of nanofiller modifiers on their organization in the polymer matrix and on the mechanical properties of nanocomposites are discussed.

Crystalline Layered Nanofillers in RCN. - To achieve complete exfoliation in polymer matrices of layered nanofillers, such as OC and nanoG, is a difficult task. It is worth discussing the reasons that prevent the exfoliation of nanofillers, moving from the study of the structure of RCN containing nanofillers with stacked layers.

Effect of Cross-Linking on Nanofiller Crystallinity. - XRD analysis was performed on nanocomposites, based on IR rubber and containing either Mt/2HT as the OC or nanoG or CNT, both in the uncured and in the cured state. The objective was to investigate the effect of the crosslinking step, avoiding the influence of the chemicals typically present in elastomeric compounds. Hence, the investigated nanocomposites contained only the rubber and the nanofiller and were cross-linked with dicumyl peroxide (DCUP) Recipes are shown in Table II for CNT, in Table III for

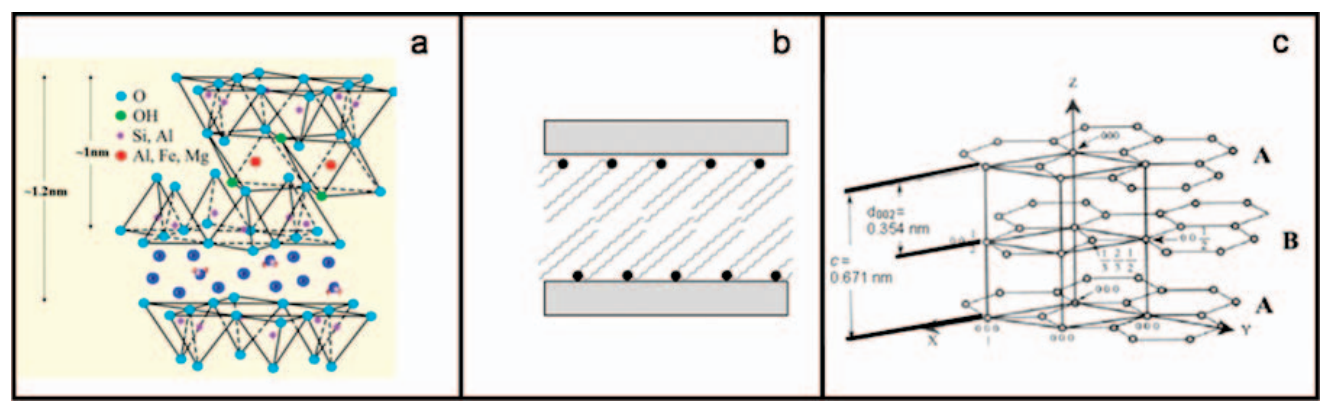

FIG. 2. - Structure of layered (nano)fillers: montmorillonite (a), organically modified clay (b), graphite (c). 


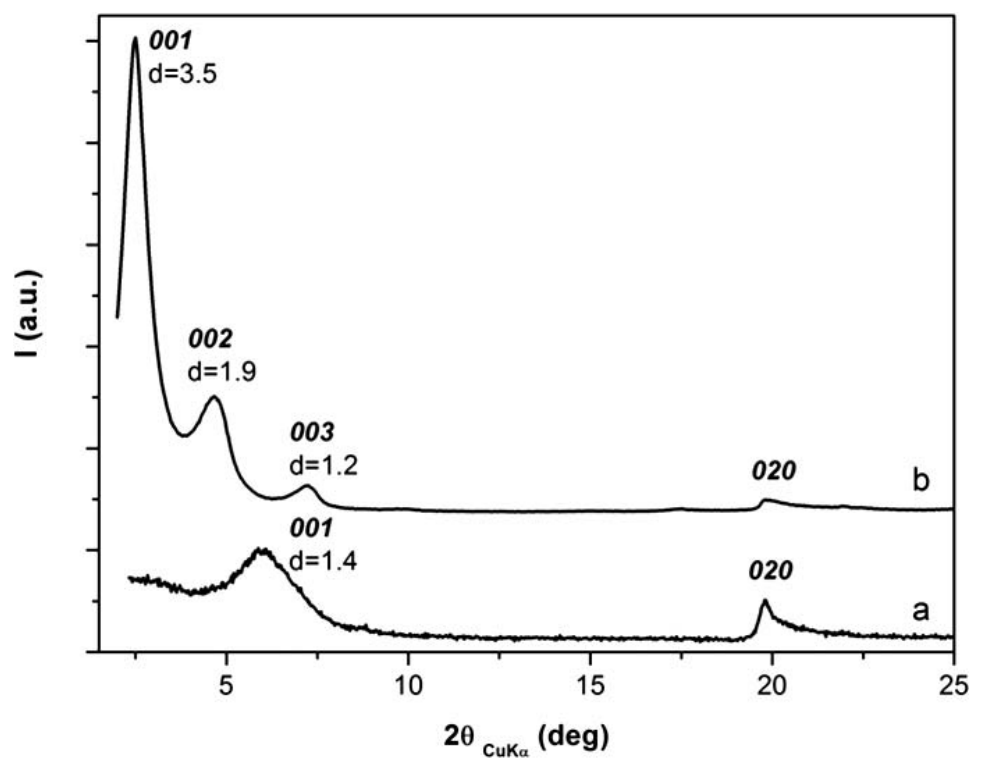

FIG. 3. - XRD pattern in the $2^{\circ}-25^{\circ} 2 \theta$ range of (a) Mt; (b) Mt with dimethylditalloylammonium (2HT) as the compensating cation.

nanoG, and in Table VI for OC. Figure 5 shows the XRD patterns, for OC (Figure 5A), CNT (Figure 5B), and nanoG (Figure 5C) based nanocomposites, and Table VIII reports the estimated number of stacked layers in the nanofillers contained either in un-cross-linked or cross-linked nanocomposites.

For CNT and nanoG, a higher number of stacked layers was found in the cross-linked composite. In the case of CNT, this finding cannot be justified with a higher number of wrapped
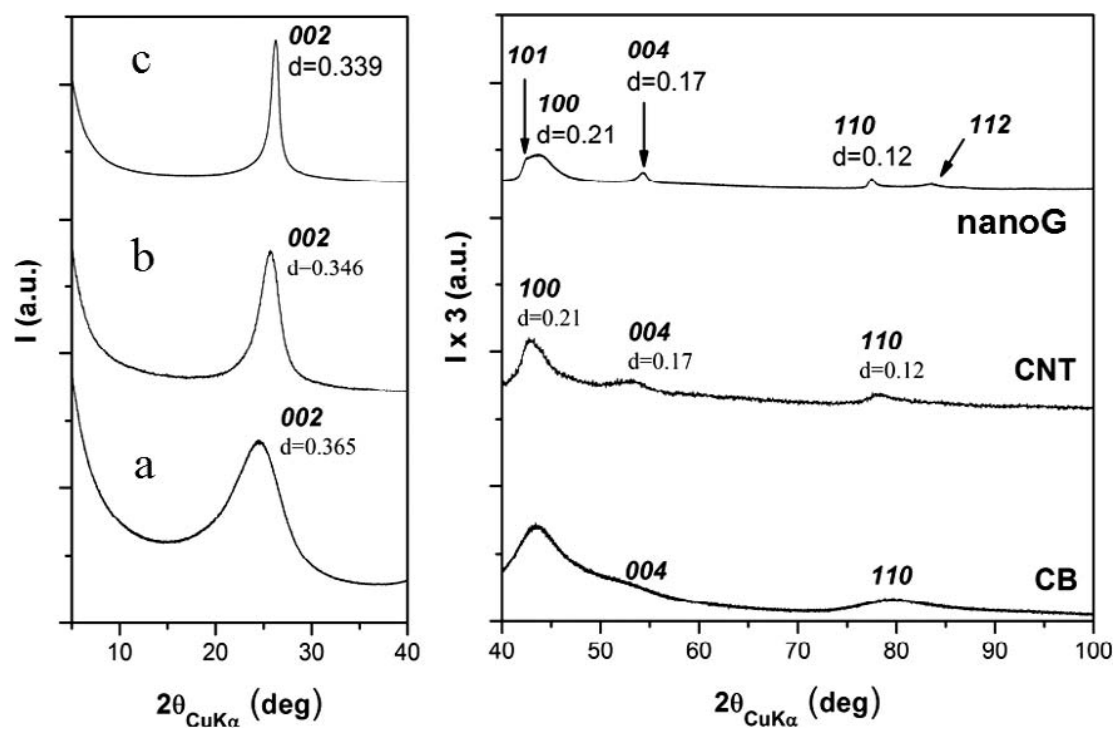

FIG. 4. - XRD pattern in the $2^{\circ}-100^{\circ} 2 \theta$ range of carbon fillers formed by layers of $\mathrm{sp}^{2}$-bonded carbon atoms: (a) CB; (b) CNT; and (c) nanoG. 
TABLE VIII

ESTIMATED NUMBERS OF STACKED LAYERS FOR OC, CNT, AND NANOG AS NANOFILlERS: IN THEIR PRISTINE STATE, IN UNCURED AND CURED

NANOCOMPOSITES

\begin{tabular}{lccc}
\hline & \multicolumn{3}{c}{ Numbers of staked layers } \\
\cline { 2 - 4 } Nanofiller & Pristine state & $\begin{array}{c}\text { Un-cross-linked } \\
\text { composite }\end{array}$ & $\begin{array}{c}\text { Cross-linked } \\
\text { composite }\end{array}$ \\
\hline OC & 5 & 8 & 8 \\
CNT & 10 & - & 14 \\
NanoG & 35 & 34 & 67 \\
\hline
\end{tabular}

layers in the cross-linked nanocomposite. Hence, these results could be explained with a better stacking of the nanofiller layers in the cross-linked nanocomposites, a consequence of the temperature and the pressure adopted in the cross-linking step. Interestingly, in the case of OC, a higher number of stacked layers, with respect to the pristine OC, was found in the un-cross-linked nanocomposite. Mixing and vulcanization thus promote a higher crystallinity of nanofillers. This can be beneficial for CNT. In fact, the slippage of CNT layers, one on top of the other, is considered to bring a potential reduction of the reinforcement effect of multiwalled CNT. However, this finding also teaches that the exfoliated nanofiller layers should be brought well apart in the polymer matrix, to prevent their reaggregation in a crystalline domain. These results are not affected, for all the nanofillers, by the presence of a nanostructured filler such as CB.

Variable Structure of OC as the Nanofiller. - Results obtained for nanoG- and CNT-based nanocomposites were not affected by the presence of low-molecular-mass ingredients, such as the ones typical of a rubber compound cross-linked with a sulfur-based system. The structure of OC was instead found to depend on such low-molecular-mass chemicals. XRD analysis was performed on nanocomposites based on IR and CB and containing Mt/2HT as the nanofiller, in the presence of the ingredients reported in Table IX.

Figure 6 shows the XRD pattern of the master batch containing IR, CB, Mt/2HT (pattern (a)), and the pattern of the un-cross-linked compound containing also all the other ingredients (pattern (b)).

At about $25^{\circ}$, the $2 \theta$ range is visible as a halo due to $\mathrm{CB}$. The region of the patterns, at low $2 \theta$ angles, where $(00 \ell)$ reflections are located, reveals that $\mathrm{Mt} / 2 \mathrm{HT}$ has a $4 \mathrm{~nm}$ interlayer distance in the master batch without other ingredients, whereas it has a $6 \mathrm{~nm}$ interlayer distance in the un-crosslinked compound. Interestingly, $\mathrm{Mt} / 2 \mathrm{HT}$ with $6 \mathrm{~nm}$ as $\mathrm{d}_{001}$ basal spacing shows more $(00 \ell)$
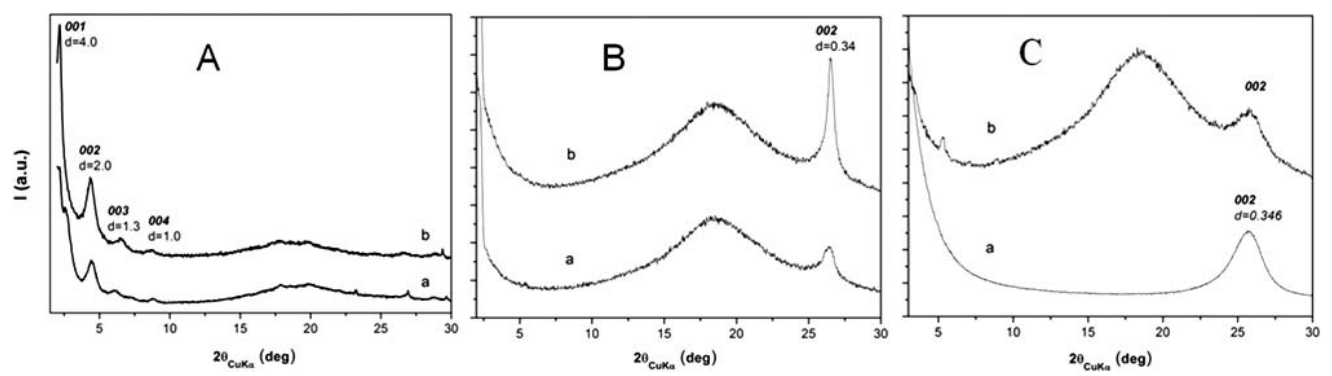

FIG. 5. - XRD patterns in the $2^{\circ}-30^{\circ} 2 \theta$ range of (a) un-cross-linked and (b) cross-linked nanocomposites containing Mt/ $2 \mathrm{HT}$ as the (A) OC, (B) nanoG, (C) CNT. 
TABLE IX

FORMULATION OF IR-BASED NANOCOMPOSITES WITH OC ${ }^{a}$ AS THE NANOFILLER

\begin{tabular}{lcccccccccc}
\hline Ingredient & IR & CB & OC & Stearic acid & ZnO & 6PPD & S & CBS & PVI & Phtalic anhydride \\
\hline $\mathrm{phr}$ & 100 & 50 & 8.3 & 2 & 4 & 2 & 2 & 1.8 & 0.3 & 1 \\
\hline
\end{tabular}

${ }^{a} \mathrm{OC}=\mathrm{Mt} / 2 \mathrm{HT}$.

reflections in the XRD pattern. This finding can be rationalized with reference to the scheme reported in Figure 7.

The intercalation of stearic acid in the interlayer space leads not only to the enlargement of the interlayer distance but also to a higher degree of order, ${ }^{32,35}$ thanks to the packing of stearic acid with the hydrocarbon tails of the ammonium cation. Solid-state synthesis of $\mathrm{Mt} / 2 \mathrm{HT}$ was performed in the absence and in the presence of stearic acid, and 4 and $6 \mathrm{~nm}$ were found as interlayer distances, respectively. ${ }^{28,29}$ Moreover, the synthesis of $\mathrm{Mt} / 2 \mathrm{HT}$ and of $\mathrm{Mt} / 2 \mathrm{HT} /($ stearic acid) was performed in the IR rubber matrix, and the XRD patterns of the nanocomposites showed the same $(00 \ell)$ reflections observed in the patterns of the OC prepared at the solid state. The variation of OC structure observed passing from the master batch to the un-cross-linked compound could be thus attributed to the intercalation of stearic acid. Figure $6 \mathrm{c}$ shows the XRD pattern of the cross-linked compound (pattern (c)). It appears that $\mathrm{Mt} / 2 \mathrm{HT}$ has $4 \mathrm{~nm}$ as an interlayer distance in the final crosslinked compound, as in the master batch. To explain this finding, the reaction of the intercalated stearic acid with other ingredients of the compound, namely, with $\mathrm{ZnO}$, can be hypothesized. To confirm this hypothesis, synthesis of $\mathrm{Mt} / 2 \mathrm{HT}$ and $\mathrm{Mt} / 2 \mathrm{HT} /$ (stearic acid) was performed at the solid state, repeating the reported procedure ${ }^{28,29}$ and then performing the reaction of Mt/2HT/SA with $\mathrm{ZnO}$. Figure 8 shows the XRD patterns of Mt/2HT (Figure 9a), Mt/2HT/(stearic acid; Figure 9b), and $\mathrm{Mt} / 2 \mathrm{HT} / \mathrm{SA}$ after the reaction with $\mathrm{ZnO}$ (Figure 9c). XRD analysis revealed the following interlayer distances: $4 \mathrm{~nm}$ and $6 \mathrm{~nm}$ for the Mt/2HT prepared in the absence and in the presence of stearic acid and $4 \mathrm{~nm}$ for $\mathrm{Mt} / 2 \mathrm{HT} /($ stearic acid) after the reaction with $\mathrm{ZnO}$.

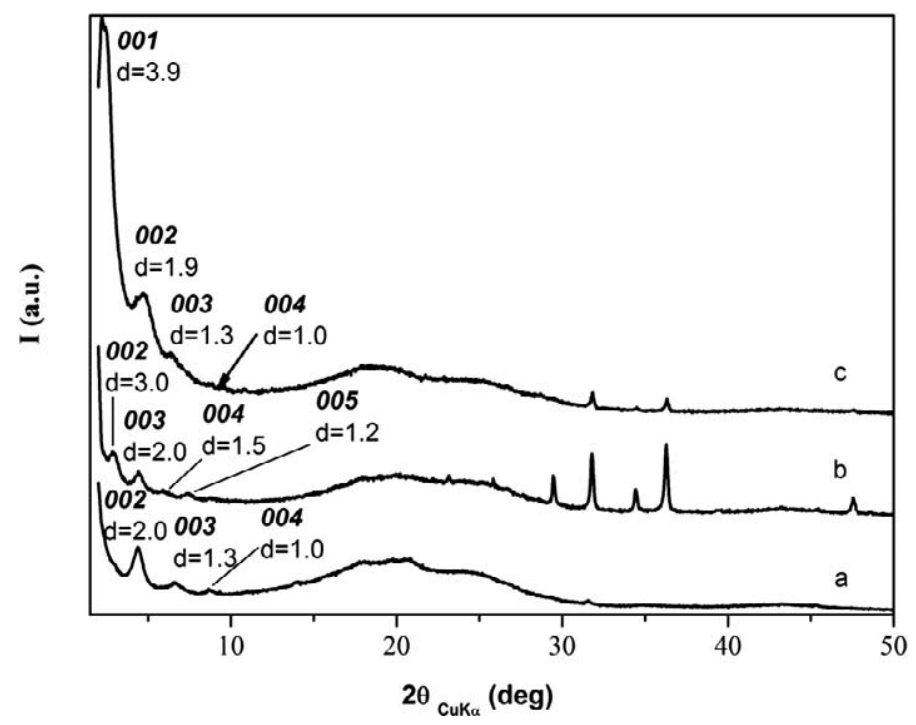

FIG. 6. - XRD patterns in the $2^{\circ}-50^{\circ} 2 \theta$ range of nanocomposites containing Mt/2HT as the OC: (a) master batch; (b) uncross-linked compound; (c) cross-linked compound. 


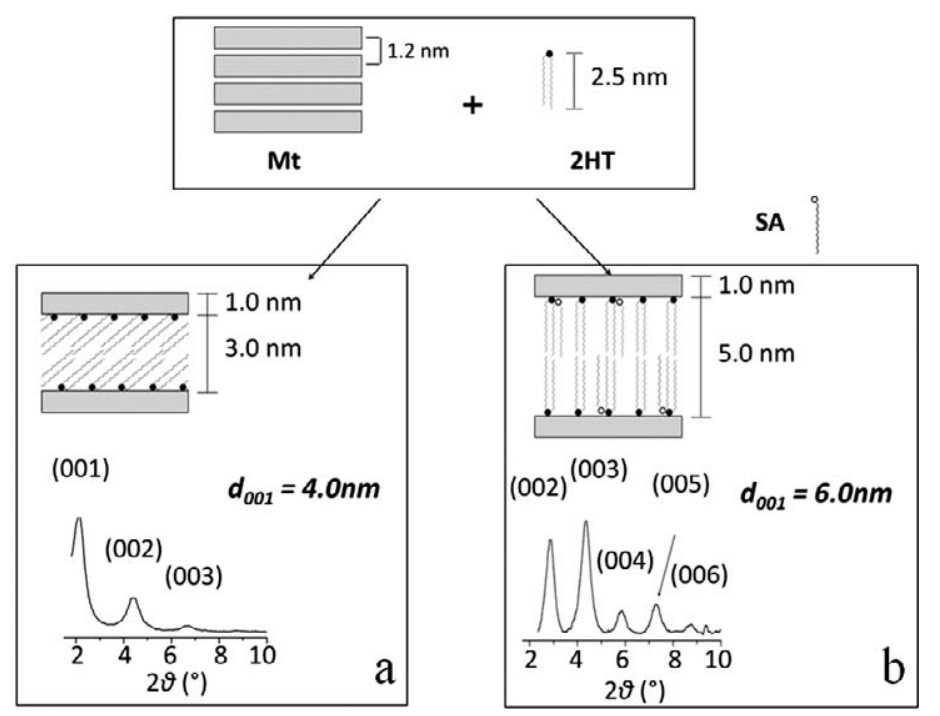

FIG. 7. - Mechanism for the formation of OC from $\mathrm{Mt}$ and $2 \mathrm{HTCl}$, in the (a) absence or in the (b) presence of stearic acid (SA).

On the basis of the results shown in these two paragraphs, it can be concluded that the structure of layered nanofillers, the degree of crystallinity, and the chemical composition can change during the preparation of the rubber compound. It is also worth commenting that low-molecular-mass chemicals can be intercalated in the clay interlayer space, reasonably more easily than polymer chains. It is worth noting that most of the clay interlayer distance variation reported in the literature
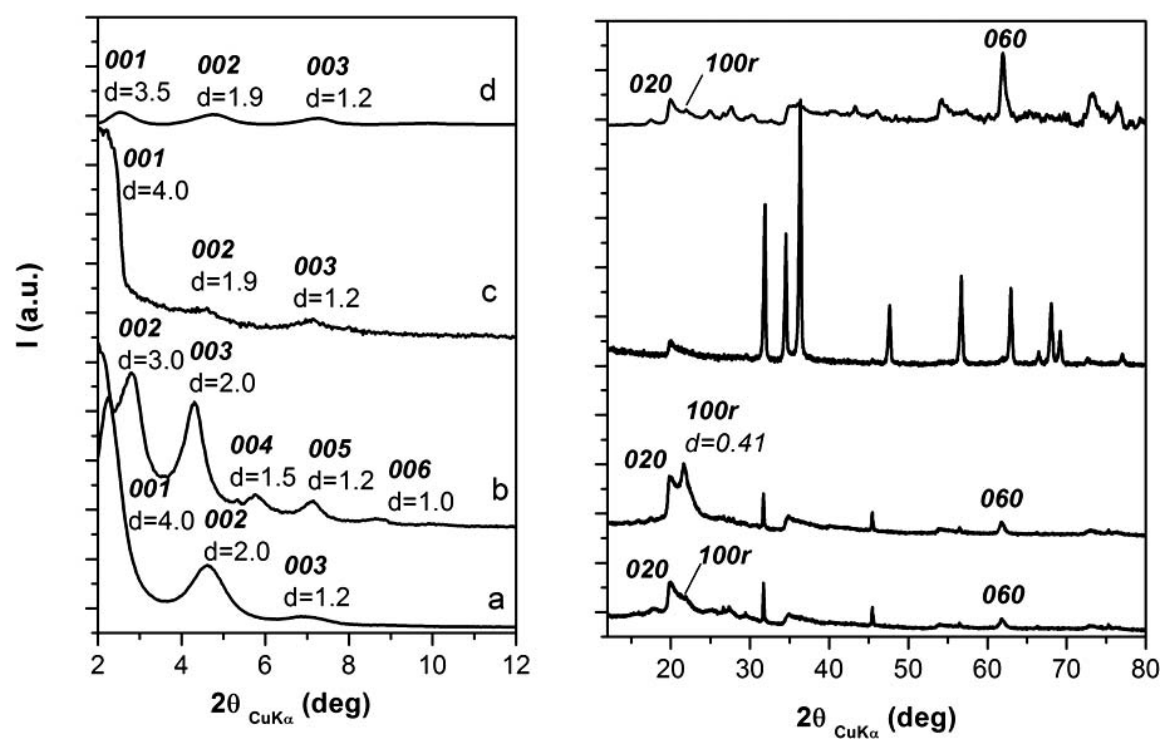

FIG. 8. - XRD patterns in the $2^{\circ}-80^{\circ} 2 \theta$ range of OC: (a) Mt/2HT prepared at the solid state; (b) Mt/2HT/(stearic acid) prepared at the solid state; (c) Mt/2HT/(stearic acid) prepared at the solid state after the reaction with ZnO; (d) Mt/2HT after ball milling. In (d), the XRD pattern intensities were corrected for polarization and Lorentz factors. For the reaction conditions, see the Experimental section. 

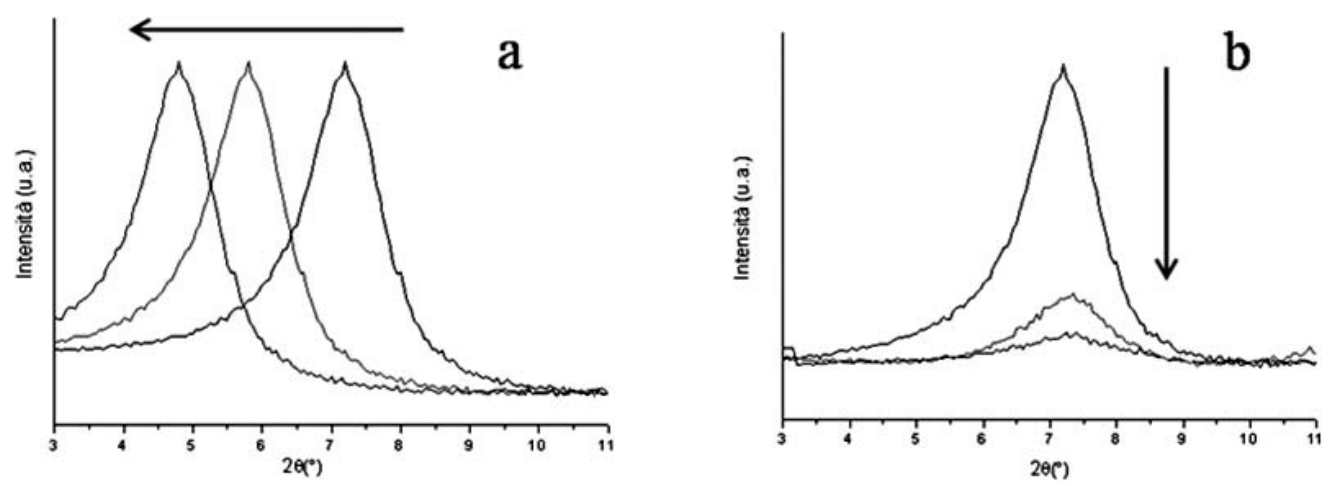

FIG. 9. - (001) reflection of OC in the XRD pattern of rubber nanocomposites: (a) shift toward lower $2 \theta$ angles; (b) decrease of intensity at the same $2 \theta$ angle.

could be explained by considering intercalation and deintercalation of low-molecular-mass substances.

Exfoliation of Layered Nanofillers in RCN. - Obtaining RCN with exfoliated clays and graphene is the subject of large research efforts, in both academic and industrial laboratories, and, as mentioned above, it is often pursued through the chemical modification of nanofillers. In the following paragraphs, the effect of the organization of the layered filler is first discussed, namely, the interlayer distance and the degree of order in the interlayer space, on the layered filler exfoliation. Ways to achieve exfoliation are then briefly summarized.

The Role of the Interlayer Distance. - To achieve OC exfoliation, most authors rely on polymer intercalation, supposed to be energetically favored by the interaction between polymer and alkylammonium chains. ${ }^{4,5}$ It is supposed that chain intercalation increases the distance between the layers and thus favors their separation. The proposed mechanism is shown in Figure 8a.

The scheme in Figure 8a shows the shifting of the (001) reflection toward lower $2 \theta$ angles, indicating the enlargement of the interlayer distance, assumed to be due to the polymer chain intercalation. One objective of our research activity was to investigate the correlation between the interlayer distance and the exfoliation of layered fillers such as OC and nanoG.

As reported in the previous paragraph, the intercalation of a long-chain fatty acid such as stearic acid leads to the expansion of the interlayer distance of the OC containing 2HT as the compensating cation. ${ }^{32,35,36}$ Recently, the intercalation of long-chain fatty acids in the interlayer space of organically modified layered silicates has been documented to promote the expansion of the interlayer distance and the improved dispersion of OC in natural rubber (NR) matrix. ${ }^{37,38}$ In these works, OC had dimethyl distearyl ammonium as the compensating cation, and the expansion of the interlayer distance $\left(\mathrm{d}_{001}\right.$ from $2.98 \mathrm{~nm}$ to a maximum value of $5.6 \mathrm{~nm}$ in the NR matrix) was obtained by melt blending, in an internal mixer, OC with docosanoic acid, with a subsequent grinding step. Easier OC exfoliation in the rubber matrix was commented, with, however, the presence of (001) reflection in the XRD pattern of the nanocomposites. On the basis of these results available in the prior art, it can be commented that OC containing compensating cations with long hydrocarbon tails and, optionally, further paraffinic chains show (to different extents) crystalline order, also in RCN. In the previous paragraph, it was commented that the intercalation of stearic acid in the interlayer space of Mt/2HT leads to the increase of the degree of order in the interlayer space. The key role in promoting such order is played by the long hydrocarbon chains, which form a crystalline packing. 
Careful inspection of the pattern in Figure 9a reveals a well-defined narrow peak at $2 \vartheta=21.7^{\circ}$, with $0.41 \mathrm{~nm}$ as the distance between crystallographic planes. This is the distance between long hydrocarbon chains in their hexagonal rotator order. In fact, this reflection is typically observed for the phase transitions of n-alkanes as rotator crystals. ${ }^{39-41}$ Such a hexagonal rotator order was reported for long-chain alkylammoniums intercalated in anionic clays (layered double hydrotalcite $)^{42}$ and in graphite oxide. ${ }^{43}$ The intensity of the peak due to such rotator order can be observed to increase by adding stearic acid in the solid-state synthesis of Mt/2HT.

The available results suggest that the expansion of the $\mathrm{OC}$ interlayer distance can also be correlated with a higher crystallinity. OC with a higher crystallinity degree should not be expected to achieve an easier exfoliation.

The Order in the Interlayer Space. - It thus seems possible to hypothesize that the exfoliation of a layered filler could be correlated with the order in the interlayer space. To verify this hypothesis, OC was prepared through the reaction of $\mathrm{Mt}$ with dimethyldioctylammonium (2O) chloride, at the solid state (as described in the Experimental section). IR-based nanocomposite was then prepared, with the formulation reported in Table IX, with $\mathrm{Mt} / 2 \mathrm{O}$ in place of Mt/2HT. Figure 10 shows the XRD patterns of pristine $\mathrm{Mt} / 2 \mathrm{O}$ and of the IR-based nanocomposite with $\mathrm{Mt} / 2 \mathrm{O}$.

The XRD pattern of pristine $\mathrm{Mt} / 2 \mathrm{O}$ is characterized by the presence of strong (001) reflection and a weak (002) reflection. $\mathrm{d}_{001}$ basal spacing is about $3.5 \mathrm{~nm}$, indicating a higher degree of tilting of the octyl chains with respect to the talloyl ones. (00 $\ell$ ) reflection cannot be observed for $\mathrm{Mt} / 2 \mathrm{O}$ in the nanocomposite. The comparison of patterns of Figure 10 with patterns shown in Figure 6 suggests that the degree of exfoliation is not necessarily correlated (for an OC) with the interlayer distance. It is worth noting that reports available in the scientific literature reveal that crystalline OC in RCN are easily observed when the compensating cations have two long hydrocarbon tails. ${ }^{33}$

Further indication on the role of the paraffinic chains in promoting the order in layered fillers was obtained by preparing nanocomposites based on IR and graphite oxide intercalation compounds with $2 \mathrm{HT}$ cations ionically bonded to the graphite oxide layers. ${ }^{44}$ Samples of graphite oxide intercalation compounds were prepared with different content of $2 \mathrm{HT}$, through the exchange reaction of a $\mathrm{GO}^{-} \mathrm{Na}^{+}$with $2 \mathrm{HTCl}$, with the optional addition of stearic acid. They showed the intense reflection due to the hexagonal rotator order of the polymethylene chains. The intensity of such reflection was higher than in Mt/2HT XRD patterns, and this can be attributed to the higher cationic exchange capacity of GO carboxylates used for the reactions with $2 \mathrm{HTCl}$. Peaks due to the rotator order were also observed in the pattern of the RCN.

How to Achieve Exfoliation of Layered Fillers? - In the literature, procedures are reported to achieve exfoliation of either OC or graphitic nanofillers.

In the case of OC, as mentioned above, most authors rely on the intercalation of polymer chains. The authors of the present article have been elaborating, over the years, an alternative proposal, summarized as follows. Crystalline layered fillers in the polymer matrix do not have polymer chains as guest in the interlayer space. The intercalation of low-molecular-mass substances is able to account for the different crystalline structures reported in the literature and for the variations of the interlayer distances. However, the polymer matrix is indeed able to pass the mixing energy to the filler, giving rise to a progressive delamination of the layered structure. In Figure $9 \mathrm{~b}$, the scheme of the so-called delamination mechanism ${ }^{36}$ is reported, which means the progressive reduction of the intensity of the (001) reflection, whose $2 \theta$ angle remains the same. Consequently, the interlayer distance of the layered filler is not modified and experiences a progressive delamination. ${ }^{36}$ The mechanical energy can be thus a precious tool to achieve the exfoliation of a layered filler. Extensively delaminated Mt/2HT was prepared by milling the OC with a planetary ball mill. ${ }^{45}$ Its XRD pattern is shown in Figure $8 \mathrm{~d}$. The $(00 \ell)$ reflections can hardly be detected, whereas the reflection due to the rotator order is still visible, to confirm that the packing energy of the paraffinic chains is a powerful driving force for assembling crystalline layered fillers. 

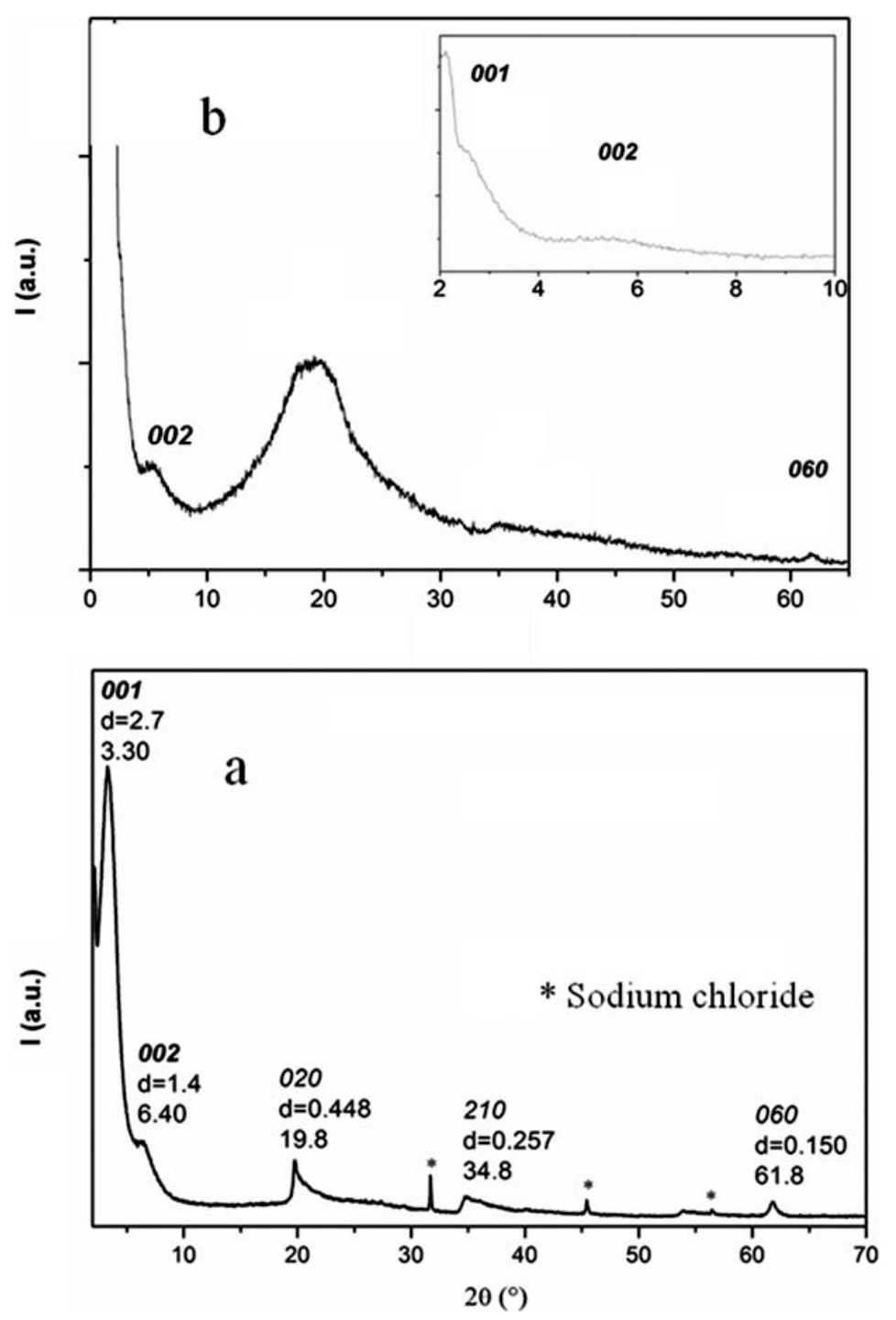

FIG. 10. - XRD patterns in the $2^{\circ}-70^{\circ} 2 \theta$ range of OC: (a) Mt/2O prepared at the solid state; (b) IR based nanocomposite containing $\mathrm{Mt} / 2 \mathrm{O}$ prepared at the solid state (master batch).

Endothermic phenomena were detected, at temperatures close to $50{ }^{\circ} \mathrm{C}$, for graphite oxide intercalation compounds ${ }^{43}$ and for OC, ${ }^{18,29}$ with $2 \mathrm{HT}$ as the compensating cation. Thanks to the attribution of the XRD pattern reflection at $21.7^{\circ}$, it is possible to explain such an endothermic phenomenon with the melting of polymethylene chains.

A promising way to achieve an easier exfoliation of clays is the preparation of OC with low crystallinity, which means a low degree of order in the interlayer space. In the previous paragraph, an example was presented of OC with a disordered interlayer space (i.e., difficult packing of interlayer guests), thanks to the selection of appropriate ammonium cation tails.

Graphene layers stacking is prevented in the literature by using solution blending of the graphitic nanofiller or latex blending of graphite oxide with appropriate rubber. Exfoliation of graphene nanoplatelets of $3 \mathrm{~nm}$ in thickness was obtained via solution mixing with styrene- 
TABLE $\mathrm{X}$

PerColation Threshold, $\phi_{\mathrm{p}}$, OF OC, CNT, AND NANOG IN RUBber MATRIX $^{a}$

\begin{tabular}{llcc}
\hline Nanofiller & \multicolumn{1}{c}{ Matrix } & $\phi_{\mathrm{p}}(\mathrm{phr})$ & Ref \\
\hline OC & neat SBR & $12^{b}$ & 46 \\
& neat NR & 8 & 47 \\
& neat IR & 6 & 48 \\
& IR +60 phr CB & 3 & 48 \\
CNT & neat IR & 7 & 49 \\
& neat IR & 9 & 50 \\
\multirow{2}{*}{ NanoG } & IR +60 phr CB & 3 & 49 \\
& neat IR & 21 & 14 \\
& neat IR & 17 & 50 \\
& IR +60 phr CB & 8 & 14 \\
\hline
\end{tabular}

${ }^{a}$ The percolation threshold was calculated through the Huber-Vilgis method. ${ }^{51}$ Round figures are indicated in the table.

${ }^{b}$ Estimated value. In ref 46, the percolation threshold was reported as $\mathrm{SiO}_{2}$ content in $\mathrm{OC}$ and was $2.7 \mathrm{vol} \% \mathrm{SiO}_{2}$.

butadiene rubber, ${ }^{11}$ whereas graphene oxide/carboxylated acrylonitrile butadiene RCN were prepared using the latex co-coagulation method. ${ }^{12,13}$ Some of the authors of this article have reported easy exfoliation of graphite oxide intercalation compounds with a large amount of compensating cations. Such intercalate compounds, presented in the previous paragraph, were prepared starting from $\mathrm{GO}^{-} \mathrm{Na}^{+}$having a very high cationic exchange capacity (higher than 7 $\mathrm{mmol} / \mathrm{g})$. The intercalate compound did not show any residual $(00 \ell)$ reflection in the IR-based nanocomposite, despite the high packing order of the hydrocarbon tails. ${ }^{44}$

\section{PART II: FILLER NETWORKING}

Filler Networks at Low Nanofiller Content. - Nanofillers evenly dispersed as individual layers are expected to form networks at very low concentrations in polymer matrices. As shown in Table X, data already available in the literature are in line with this expectation.

Some of the authors of this article prepared nanocomposites with $\mathrm{OC},{ }^{48} \mathrm{CNT},{ }^{49}$ and nanoG ${ }^{14}$ as the nanofillers, at different nanofiller contents. By applying the Huber-Vilgis method, ${ }^{51}$ the excess of the nanocomposite initial modulus with respect to the matrix modulus was reported versus the nanofiller volume fraction in a double logarithmic plot, and the percolation threshold was evaluated as the filler content at which discontinuity was observed. Nanofillers' percolation thresholds were found to be much lower than those typical of the so-called nanostructured fillers, such as CB or silica. These data refer to nanofillers in neat polymer matrices. As mentioned in the Introduction, this article is focused on nanocomposites containing a hybrid filler system, with the nanofiller combined with a nanostructured filler such as CB. Data are also available with regard to nanocomposites with a large amount of $\mathrm{CB}(60 \mathrm{phr})$ and nanofillers in different concentrations. ${ }^{14,48,49}$ Initial modulus data were determined for these nanocomposites, and a discontinuity was also observed in the Huber-Vilgis plot, as if CB and the nanofiller were able to establish a hybrid filler network. Table $\mathrm{X}$ reports the value of nanofiller content at which the mentioned discontinuity occurs: this sort of "threshold value" is appreciably lower than that required to have nanofiller percolation in the neat polymer matrix. TEM analysis revealed the presence of continuous hybrid 


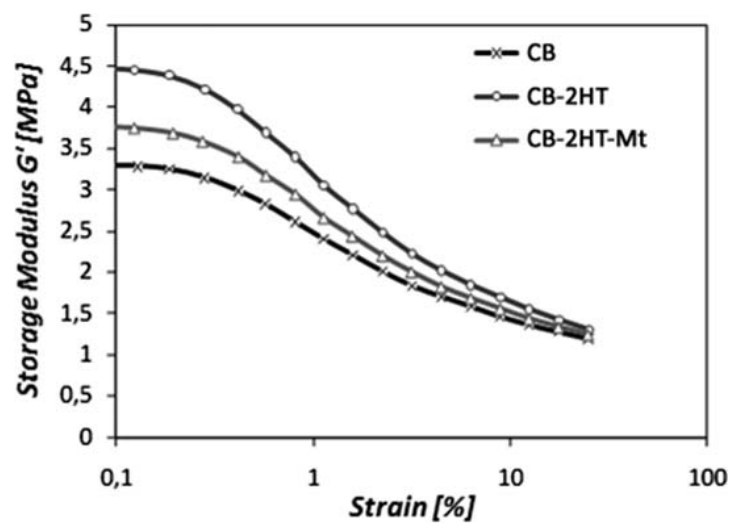

FIG. 11. - Storage shear modulus $G^{\prime}$ versus strain amplitude for IR-based composites containing CB, CB-2HT, or CB2HT-Mt.

filler networks in nanocomposites with nanofiller content above the threshold value for all of the systems: OC-CB, ${ }^{48} \mathrm{CNT}-\mathrm{CB},{ }^{49}$ and nanoG-CB. ${ }^{14}$

Origin of the Interaction between $C B$ and Nanofillers. - Studies on zeta potential, whose validity was reported also for polymer nanocomposites, ${ }^{24,52,53}$ are in favor of the interaction between $\mathrm{CB}$ and the nanofiller. A pronounced interaction between carbon allotropes is intuitive. The hybrid filler network formed by $\mathrm{CB}$ and $\mathrm{OC}$ could instead be considered, to some extent, unexpected. A key role in promoting the interaction of $\mathrm{OC}$ with $\mathrm{CB}$ has been recently attributed to the clay compensating cation, with reference to the cation- $\pi$ interaction between the ammonium cation and the $\mathrm{CB} \pi$ system. $^{54}$ The intimate interaction between $\mathrm{CB}$ and an ammonium salt (e.g., cetyltrimethyl ammonium bromide) has been known for a long time in the rubber field. ${ }^{55}$

Figure 11 shows clear evidence of such intimate interaction: the shear modulus at low strain amplitude is remarkably enhanced by adding $2 \mathrm{HTCl}$ ( $4.2 \mathrm{phr}$ ) to a composite containing $100 \mathrm{phr}$ of IR. TEM analysis revealed ${ }^{54}$ that the presence of the ammonium salt improved CB dispersion in the matrix: micrometer $\mathrm{CB}$ agglomerates were not visible, and the secondary network made by $\mathrm{CB}$ aggregates was fine and continuous. The further addition of $\mathrm{Mt}$, replacing the same volume fraction of CB ( $4.5 \mathrm{phr}$ ) and adopting equal molarity between the ammonium salt and the exchangeable $\mathrm{Na}^{+}$ cations (in $\mathrm{Mt}$ ), reduced the effects of the onium on the shear modulus at low deformation, as $\mathrm{Mt}$ competes with $\mathrm{CB}$ for the interaction with the ammonium cation. In the graph of Figure 11, the $\mathrm{CB} /$ $\mathrm{Mt} / 2 \mathrm{HT}$ system provides the intermediate curve.

Interactive Effect between $C B$ and the Nanofiller on Mechanical Reinforcement. Nanofillers such as OC, CNT, and nanoG, thanks to the hybrid filler networks formed with CB, can thus bring about substantial enhancement of the mechanical reinforcement of RCN. In fact, clear enhancement of the initial modulus was documented when $\mathrm{OC},{ }^{48} \mathrm{CNT},{ }^{49}$ and nanoG (ref 14) were added to IR-based composite containing CB (60 phr). Figure 12 shows the elaboration of the experimental initial modulus data of the obtained nanocomposites.

In the graphs of Figure 12, points are due to experimental data, whereas the dotted lines indicate

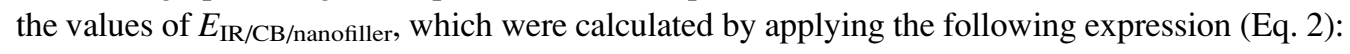

$$
E_{\mathrm{IR} / \mathrm{CB} / \text { nanofiller }}=E_{\mathrm{IR} / \mathrm{CB}}+\left[E_{\mathrm{IR} / \text { nanofiller }}-E_{\mathrm{IR}}\right]
$$

where $E_{\mathrm{IR}}$ is the initial modulus of the IR matrix, $E_{\mathrm{IR} / \mathrm{CB}}$ is the initial modulus of the composite containing $60 \mathrm{phr}$ of $\mathrm{CB}$, and $E_{\mathrm{IR} / \text { nanofiller }}$ is the initial modulus of the composite containing a given amount of nanofiller in the neat IR matrix. Equation 2 is the expression of a simple additive rule, 

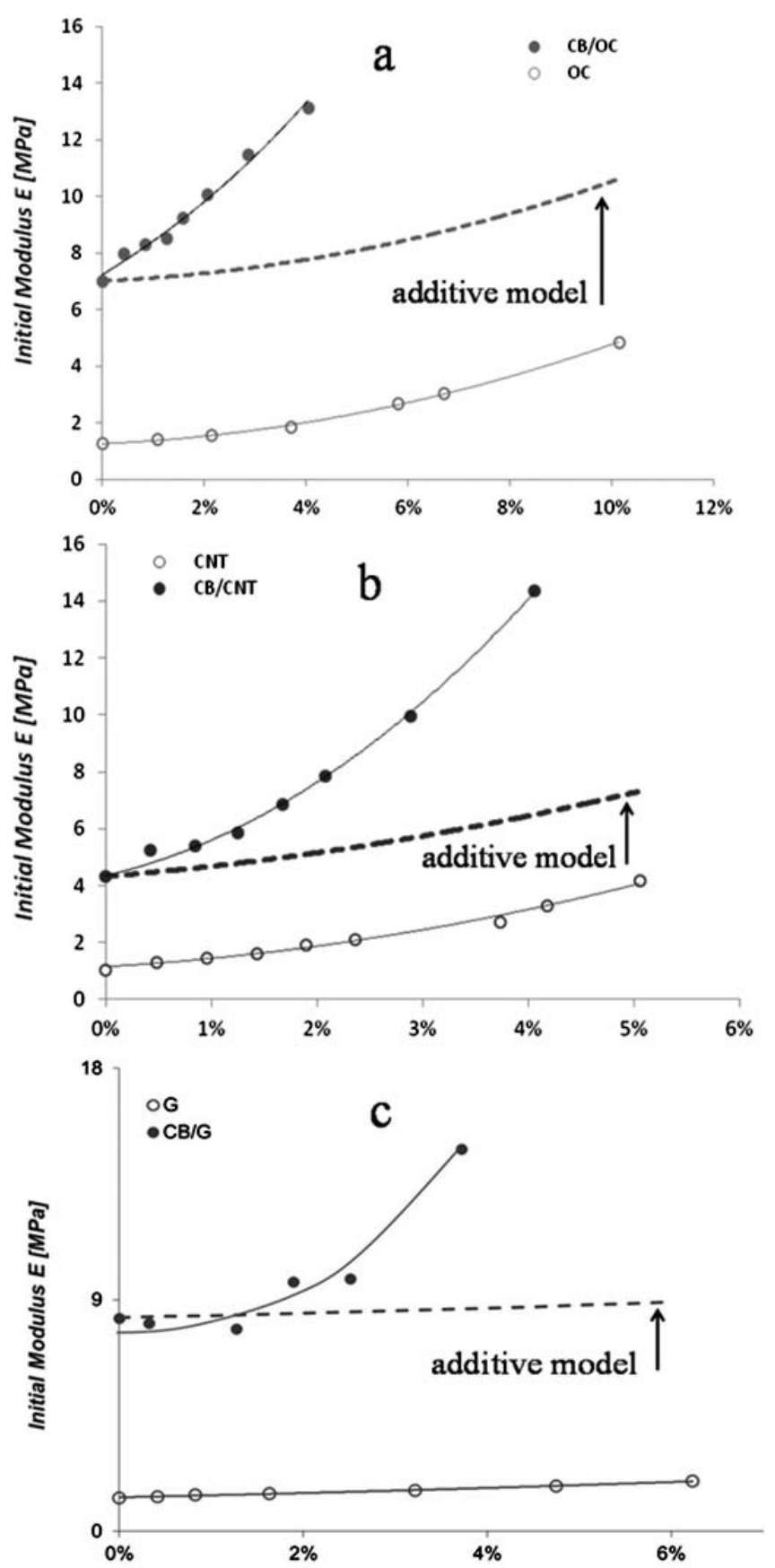

Nanofiller content (\% vol)

FIG. 12. - E initial modulus values for nanocomposites containing: (a) OC; (b) CNT; (c) nanoG. Experimental values: $\bullet$, $\circ$. Values calculated according to the "additive model" (Eq. 2): - - Experimental values: $\circ$ refer to nanocomposites with nanofiller in the neat polymer matrix, $\bullet$ refer to nanocomposites with nanofiller in the polymer matrix containing $60 \mathrm{phr}$ of CB. 


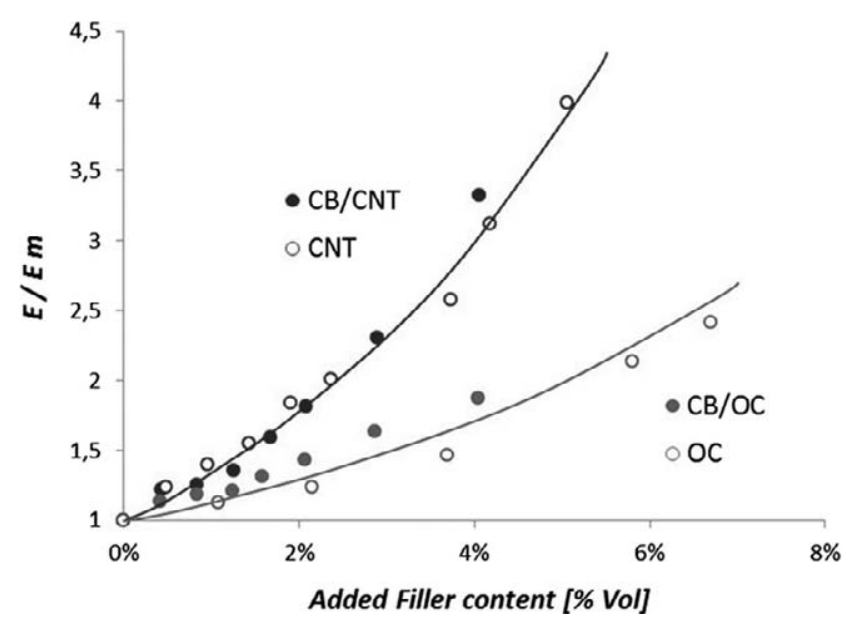

FIG. 13. $-E / E_{\mathrm{m}}$ ratio $\left(E_{\mathrm{m}}=\right.$ initial modulus of the matrix $)$ for nanocomposites containing either OC or CNT as the nanofillers: in the neat polymer matrix $(\circ)$, in the polymer matrix containing $60 \mathrm{phr}$ of $\mathrm{CB}(\bullet)$.

valid under the hypothesis that no interaction occurs between the two fillers. ${ }^{56}$ For all of the three systems (CB-OC, CB-CNT, and CB-nanoG), interactive effects are shown: the combination of CB and the nanofiller leads to initial modulus values much higher than those calculated through the simple addition of the two initial moduli of the composites containing only $\mathrm{CB}$ ( $60 \mathrm{phr})$ and only the nanofiller.

The enhancement of the matrix modulus is expressed by the $E / E_{\mathrm{m}}$ ratio, that is, by the $E_{\mathrm{IR} / \text { nanofiller }} / E_{\mathrm{IR}}$ ratio in the case of neat IR as the matrix and by the $E_{\mathrm{IR} / \mathrm{CB} / \text { nanofiller }} / E_{\mathrm{IR} / \mathrm{CB}}$ ratio in case the matrix is IR $+60 \mathrm{phr}$ of $\mathrm{CB}$. Interestingly, Figure 13, which refers to OC and CNT as the nanofillers, shows that the enhancement of the matrix modulus does not depend on the composition of the matrix (which can be with or without $\mathrm{CB}$ ) and depends only on type and amount of nanofiller. Therefore, the modulus of the matrix, thanks to the addition of the nanofiller, is enhanced by a factor that appears to be a feature of the nanofiller.

Effect of Nanofiller Exfoliation. - The formation of hybrid filler networks should be favored by the high aspect ratio of nanofillers. In fact, as was revealed by TEM micrographs, CNT are able to wrap and join $\mathrm{CB}$ aggregates. ${ }^{49}$ One could expect that nanofillers dispersed as individual layers form hybrid networks with $\mathrm{CB}$ more easily than nanofillers' aggregates. Counterintuitive results were instead collected with OC. Figure 14 shows the plot of the shear storage modulus $G^{\prime}$ versus the strain amplitude (Figure 14a) and the so-called master curves for the dependence of the storage modulus on frequency (Figure 14b) for composites, whose formulations are in Table I, containing either only $\mathrm{CB}, \mathrm{CB}$ with intercalated $\mathrm{OC}$, or $\mathrm{CB}$ with delaminated $\mathrm{OC}$.

Intercalated OC was the commercially available Mt/2HT (Dellite 67G), and delaminated OC was obtained from intercalated OC through ball milling, as reported above.

Intercalated OC appears to give rise to a more pronounced filler networking, as it is shown by the higher values of $G^{\prime}$ at low strain amplitude, by the stronger reduction of $G^{\prime}$ with the strain amplitude, and by the expansion of the rubbery plateau at low frequencies, which suggests reduced mobility for the polymer chains. These findings could be explained with the higher volume fraction of intercalated OC, as the intercalated alkylammoniums contribute to the intercalated OC volume, whereas they essentially are modifiers of delaminated OC.

Interactive Effects between Carbon Allotrope Fillers. - Data shown in Figure 12 and in Figure 13 refer to nanocomposites that contain a large amount of CB (60 phr) and minor amounts of 

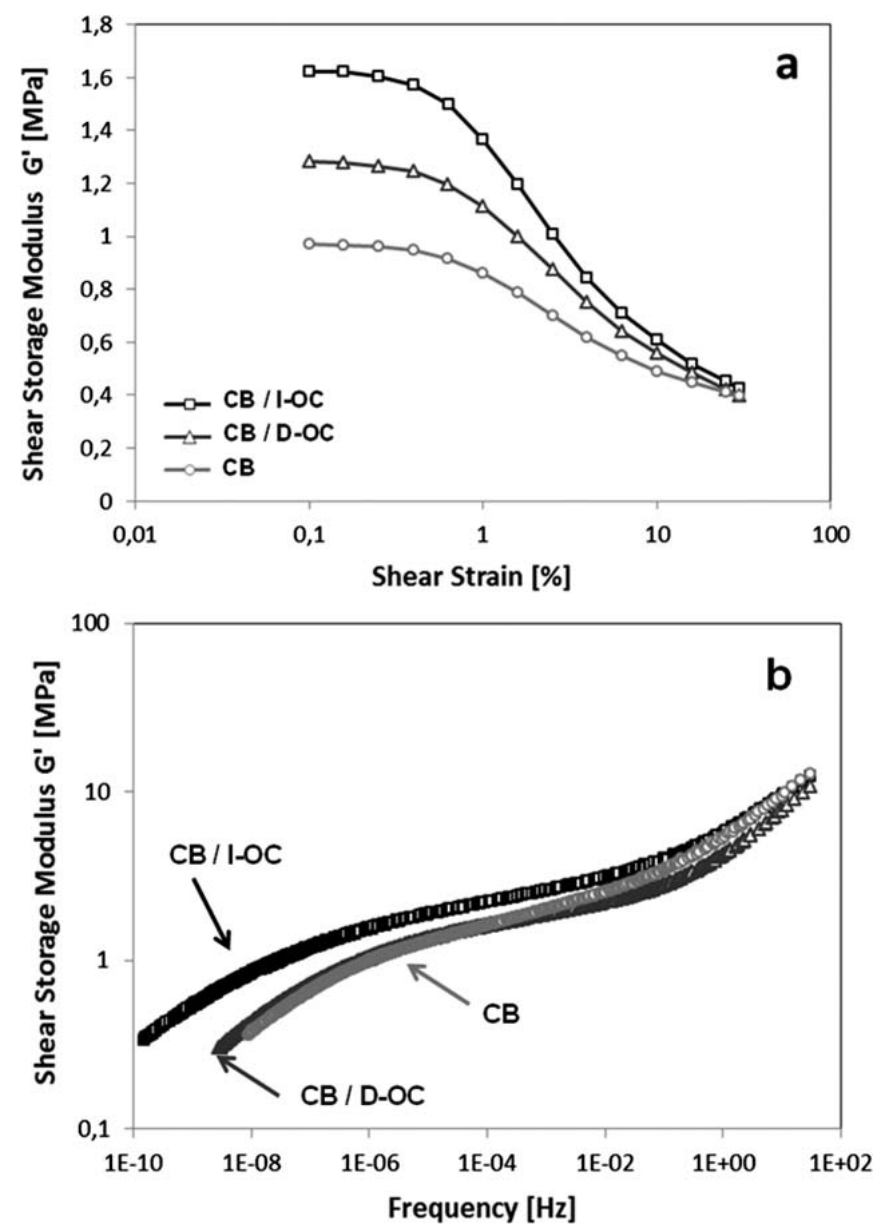

FIG. 14. - Storage shear modulus $G^{\prime}$ versus (a) strain amplitude and (b) master curves for IR-based master batches, containing $\mathrm{CB}, \mathrm{CB} /$ delaminated $\mathrm{OC}, \mathrm{CB} /$ intercalated $\mathrm{OC}$.

nanofillers and that are cross-linked with a sulfur-based system. To avoid the effects due to the different filler contents, binary composites were prepared, based on IR as the polymer matrix and filler a and filler b, with $\Phi_{\mathrm{a}}=\Phi_{\mathrm{b}}$ and $\Phi_{\mathrm{a}}+\Phi_{\mathrm{b}}$ as total filler volume fraction. To avoid effects due to the organic moiety of nanofillers, only carbon nanofillers, CNT and nanoG, without any modifiers, were used. To avoid the influence of the complex chemistry of a sulfur-based cross-linking system, composites were cross-linked with peroxide. Composites were prepared with only one carbon filler or with a carbon filler combined with $\mathrm{CB}$, maintaining the same total volume fraction. Formulations are reported in Table II, Table III, Table IV, and Table V. Filler a and filler b are thus two different carbon allotropes or two parts of the same filler.

The modulus of the composites at low strain amplitude $\left(G_{\gamma \min }^{\prime}, \gamma \min =0.1 \%\right)$ was determined through torsion measurements. The interaction between filler a and filler $\mathrm{b}$ was studied calculating the excess value of the modulus, $\Delta G_{\gamma \min }^{\prime}$, defined as the difference between the values experimentally determined and the values calculated through Eq. 3, by applying the additive model $^{56}$ :

$$
G_{\mathrm{c}}^{\prime}\left(\phi_{\mathrm{a}}, \phi_{\mathrm{b}}\right)=G_{\mathrm{a}}^{\prime}\left(\phi_{\mathrm{a}}\right)+G_{\mathrm{b}}^{\prime}\left(\phi_{\mathrm{b}}\right)-G_{\mathrm{m}}^{\prime}
$$



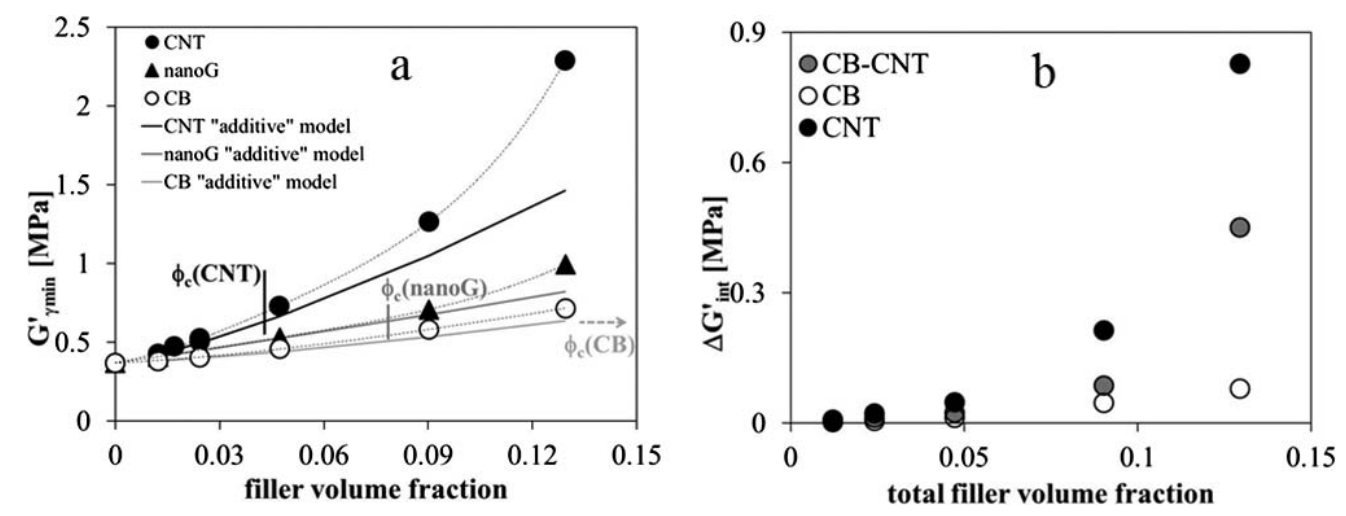

FIG. 15. - (a) $G_{\gamma \min }^{\prime}$ versus filler volume fraction for CB-, CNT-, and nanoG-filled composites; broken lines indicate values predicted by the additive model (Eq. 3); the percolation threshold of each system (see Table X) is also displayed. (b) Interactive and autointeractive terms as a function of the total filler volume fraction for nanocomposites filled with CNT, CB, and CB-CNT.

where $G_{\mathrm{c}}^{\prime}\left(\phi_{\mathrm{a}}, \phi_{\mathrm{b}}\right)$ is $G_{\gamma \min }^{\prime}$ of a composite with the two fillers $a$ and $b$, with volume fractions $\phi_{\mathrm{a}}$ and $\phi_{\mathrm{b}}$, respectively, and index $c$ stays for composite, $G_{\mathrm{m}}^{\prime}, G_{\mathrm{a}}^{\prime}\left(\phi_{\mathrm{a}}\right)$, and $G_{\mathrm{b}}^{\prime}\left(\phi_{\mathrm{b}}\right)$ are values of the modulus of the neat polymer matrix $m$, of the composite with only filler a (volume fraction $\phi_{\mathrm{a}}$ ), and of the composite with only filler b (volume fraction $\phi_{\mathrm{b}}$ ), respectively. $\Delta G_{\gamma \min }^{\prime}$ was taken as indication of the nonlinearity of the dynamic storage modulus, a consequence of the interaction between filler a and filler $b$. When filler $a$ and filler $b$ were two different carbon allotropes, the interactive effect between the two carbon allotropes was evaluated. When filler a and filler $b$ were two parts of the same filler, a sort of autointeractive term was estimated. As shown in Figure 15a, the highest autointeractive term values, $\Delta G_{\gamma \min }^{\prime}$, were calculated for the composites, with CNT as the only filler, to indicate that CNT promotes the largest nonlinearity of the dynamic-mechanical properties of the composites. $\Delta G_{\gamma \min }^{\prime}$ values of CB-based composites were remarkably increased by CNT (as shown in Figure 15b), whereas they remained substantially unaltered by nanoG.

Figure 16 shows that nanofillers cause the enhancement of the matrix modulus by a multiplication factor, defined as $k=G_{\text {nanofiller }}^{\prime}\left(\phi_{\text {nanofiller }}\right) / G_{\mathrm{m}}^{\prime}$ for single-filler composites and $k=$

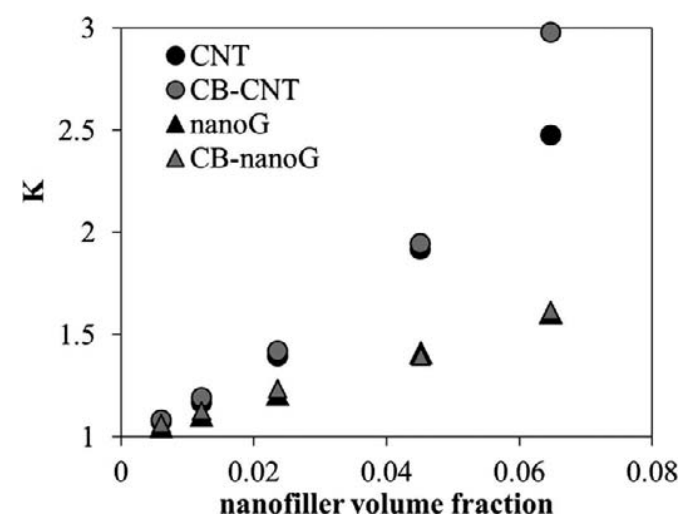

FIG. 16. $-k$ factor versus nanofiller volume fraction for the following carbon filler systems: CNT and CB-CNT, nanoG and CB-nanoG. 


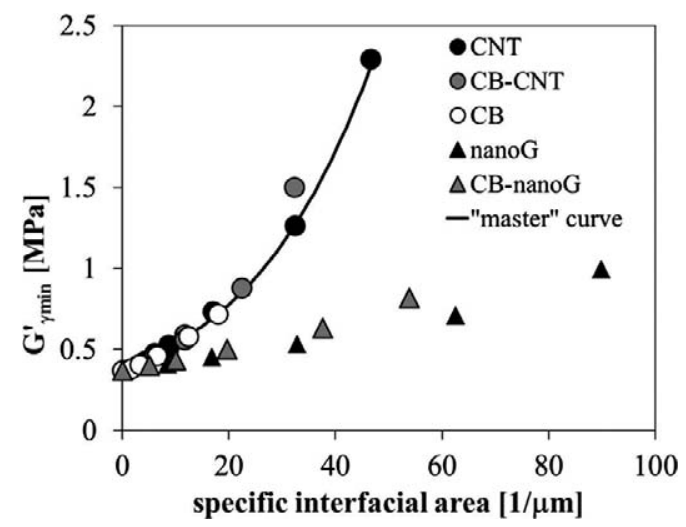

FIG. 17. $-G_{\gamma \min }^{\prime}$ values as a function of the specific interfacial area for all the composites containing the carbon fillers. The master curve averaging the CNT, CB, and CNT-CB systems is shown as well.

$G_{\mathrm{c}}^{\prime}\left(\phi_{\text {nanofiller }}, \phi_{\mathrm{CB}}\right) / G_{\mathrm{CB}}^{\prime}\left(\phi_{\mathrm{CB}}\right)$ for hybrid filler composites, which depends only on the nanofiller type and content, regardless of the matrix composition, that can be with or without $\mathrm{CB}$.

This multiplication factor appears as a sort of fingerprint for the nanofiller and is evidently higher for CNT than for nanoG. These results confirm the findings discussed in the previous paragraph.

To attempt the interpretation of such results, experimental $G_{\gamma \min }^{\prime}$ values of composites were plotted versus the specific filler-polymer interfacial area, evaluated on the basis of BET surface area measurements. Figure 17 shows that points referring to CNT- and/or CB-based composites lie on the same master curve, whereas points due to nanocomposites with nanoG are well below such a master curve.

A potential explanation for the lower $G_{\gamma \min }^{\prime}$ values obtained for the nanoG-based nanocomposites is based on the surface area of nanoG effectively accessible to the polymer chains. As reported in the Experimental section, despite the very high value of surface area determined through BET analysis, nanoG revealed an appreciably lower value of phthalate absorption. This could be explained by the high degree of stacking of nanoG layers, revealed by the XRD pattern shown in Figure 5b.

Storage Modulus of Nanocomposites with a Hybrid Filler System. - Figure 16 shows that the multiplication factor, $k$, does not depend on the composition of the matrix (which can be either neat or filled with CB) and depends only on the type and amount of nanofiller. Therefore, the following equation can be written:

$$
k\left(f_{\text {nanofiller }}\right)=G_{\text {nanofiller }}^{\prime}\left(\phi_{\text {nanofiller }}\right) / G_{\mathrm{m}}^{\prime}=G_{\mathrm{c}}^{\prime}\left(\phi_{\text {nanofiller }}, \phi_{\mathrm{CB}}\right) / G_{\mathrm{CB}}^{\prime}\left(\phi_{\mathrm{CB}}\right)
$$

with $k\left(\phi_{\text {nanofiller }}\right)$ independent of $\phi_{\mathrm{CB}}$.

Equation 4 shows that the modulus of the composite $G_{\mathrm{c}}^{\prime}$ with both nano and nano-structured fillers can be obtained by multiplying the moduli of composites containing only one filler, normalizing this product with the respect to the matrix modulus, as follows:

$$
G_{\mathrm{c}}^{\prime}\left(\phi_{\text {nanofiller }}, \phi_{\mathrm{CB}}\right)=\left(G_{\text {nanofiller }}^{\prime}\left(\phi_{\text {nanofiller }}\right) \cdot G_{\mathrm{CB}}^{\prime}\left(\phi_{\mathrm{CB}}\right)\right) / G_{\mathrm{m}}^{\prime}
$$

\section{PART III: DYNAMIC AND QUASI-STATIC MECHANICAL BEHAVIOR AT MEDIUM AND LARGE STRAIN}

Filler Networks at Low Nanofiller Content. - Nanofillers are known to cause a remarkable reduction of the storage modulus as the strain amplitude increases, which means a remarkable 

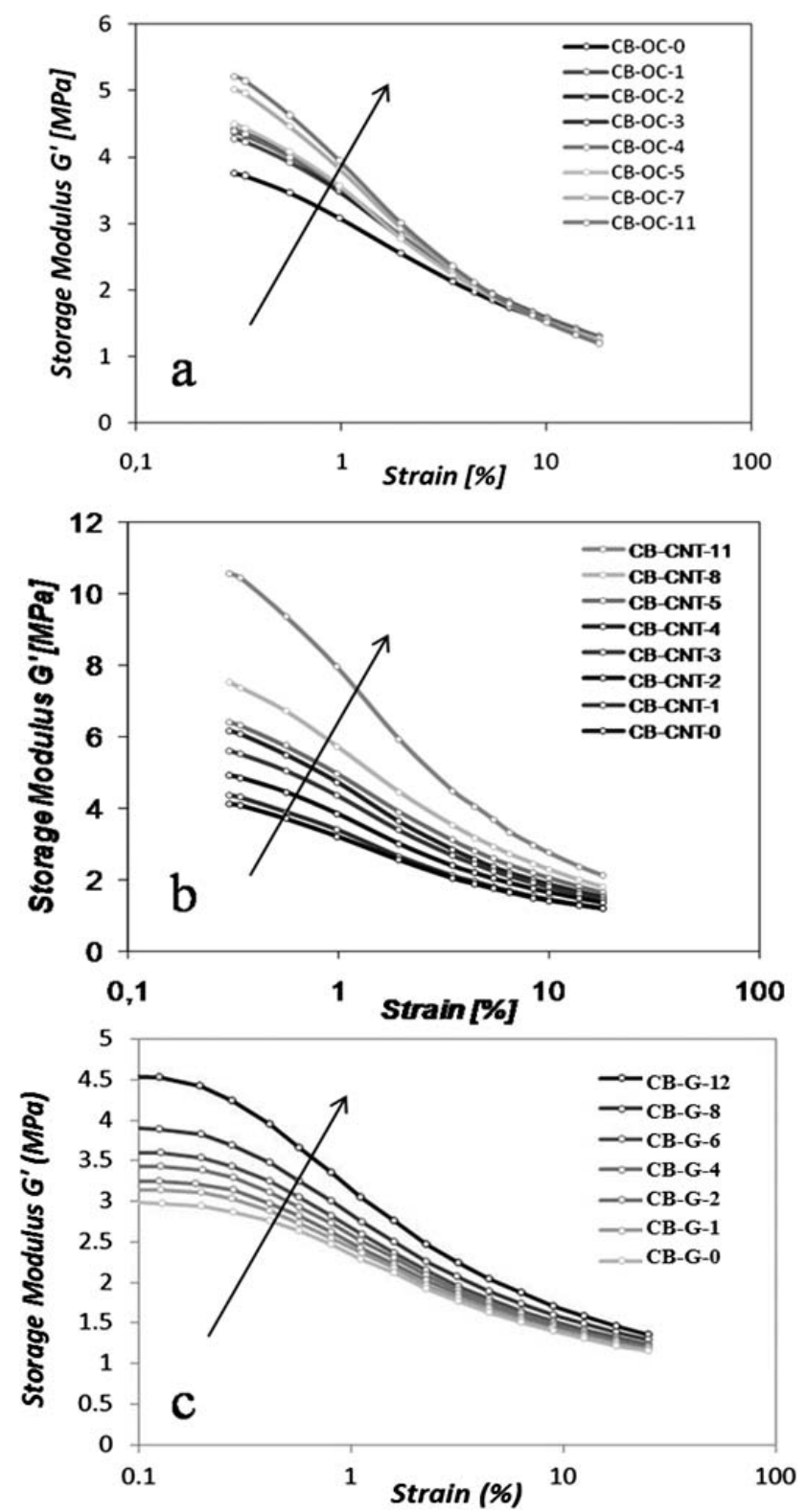

FIG. 18. - Storage shear modulus $G^{\prime}$ versus strain amplitude for IR-based nanocomposites containing CB (60 phr) and: (a) OC; (b) CNT; (c) nanoG. The arrow indicates increasing nanofiller content.

Payne effect. ${ }^{57}$ Such nonlinearity occurs for nanofillers in neat rubber matrices and is more evident in matrices containing CB. ${ }^{14,48,49}$ The plot of $G^{\prime}$ versus strain is shown in Figure 11 for the CB/OC system. The same plot is shown in Figure 18 for nanocomposites with OC, and CNT, nanoG, respectively. In the graphs of Figure 18, it is evident that the Payne effect increases with the nanofiller content.

Research on RCN is nowadays aimed at achieving a stable interaction between the polymer matrix and the nanofiller. One objective of our research activity was to investigate the medium- and 

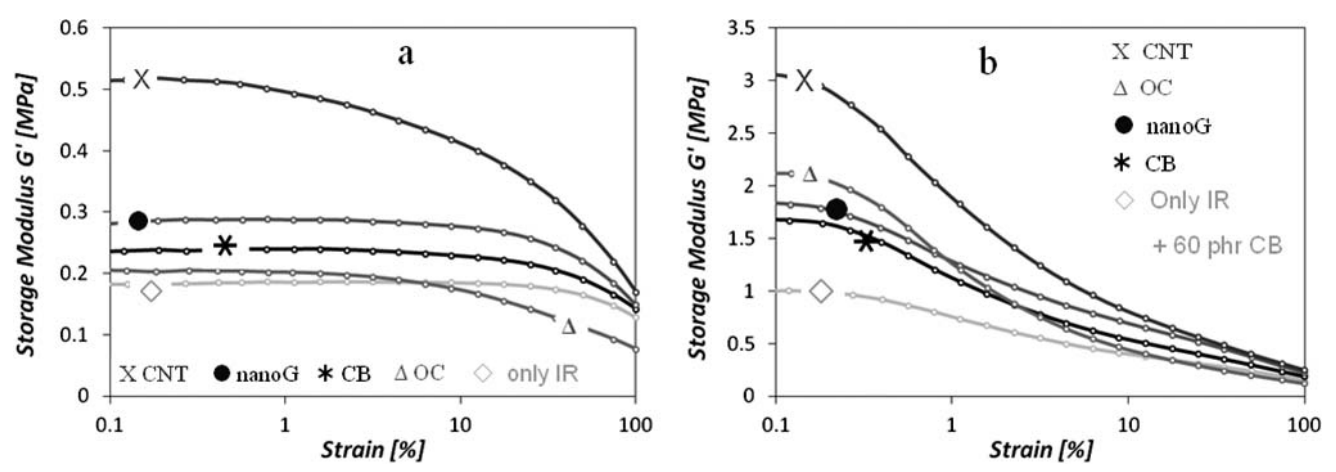

FIG. 19. - Storage shear modulus $G^{\prime}$ versus strain amplitude for peroxide cross-linked IR-based composites. The matrix is: (a) neat IR or (b) IR +60 phr of CB. Curves refer to composites without any added filler $(\diamond)$ or containing 12 phr of: either OC $(\Delta)$, or CNT $(\mathrm{X})$, or CB $(*)$.

long-range mechanical behavior of nanocomposites, with the aim of ascertaining if the increase of the strain amplitude brings about the disruption of filler-filler and filler-matrix interactions, with the consequent loss of the mechanical reinforcement.

IR-based composites were prepared, containing $12 \mathrm{phr}$ of OC, CNT, or nanoG. A composite containing $12 \mathrm{phr}$ of CB was as well prepared, for the sake of comparison. Moreover, $12 \mathrm{phr}$ of the same fillers (OC, CNT, nanoG, CB) was added to IR-based composite containing 60 phr of CB. Formulations are reported in Table VI and Table VII.

As discussed above, the ammonium cation of OC interacts with the sulfur-based cross-linking system, leading to the increase of the cross-linking network density. To avoid the influence of such interaction and thus to have a reliable comparison among the different composites, cross-linking was performed with dicumyl peroxide.

Figure 19 shows the plots of $G^{\prime}$ versus the strain amplitude for composites based on the neat IR matrix (Figure 19a) or on the matrix containing $60 \mathrm{phr}$ of CB (Figure 19b).

It is evident that CNT leads to the highest values of $G^{\prime}$, although the difference with the other carbon fillers faints as the strain amplitude increases. Interesting indeed is the behavior of OC. In the absence of CB ( $60 \mathrm{phr}$ ), OC promotes a low $G_{\gamma \min }^{\prime}$ value, although its concentration is above the percolation threshold. In the presence of $\mathrm{CB}(60 \mathrm{phr})$, the OC-based nanocomposite achieves high $G^{\prime}$ values at low deformation. A strong reduction of $G^{\prime}$ values is, however, observed as the strain amplitude increases.

Figure 20 shows the nominal stress-nominal strain curves for the same composites.

It is definitely worth noting that CNT leads to higher values of stress at a given elongation, also for strain values close to $200 \%$. The elongation at break of nanocomposites with CNT is substantially lower than that of the other composites. The effects on the stress values by nanoG and $\mathrm{CB}$ appear very similar. The elongation at break with nanoG is appreciably larger than with $\mathrm{CB}$, as expected for a layered filler. The curves of the OC-based nanocomposites show the lowest values of stresses at all the elongations. In IR-based composites, the reinforcement under strain, is also affected by the strain-induced crystallization mechanism, and data on this phenomenon (not available at present) are needed to provide a more accurate interpretation of these results.

These findings show that CNT are able to promote the mechanical reinforcement of rubber matrices, in the absence and in the presence of a nanostructured filler such as $\mathrm{CB}$, at low and high deformations, independently of the cross-linking system. Moreover, these results confirm that OC easily form hybrid filler networks with $\mathrm{CB}$ and suggest that a large part of the mechanical 

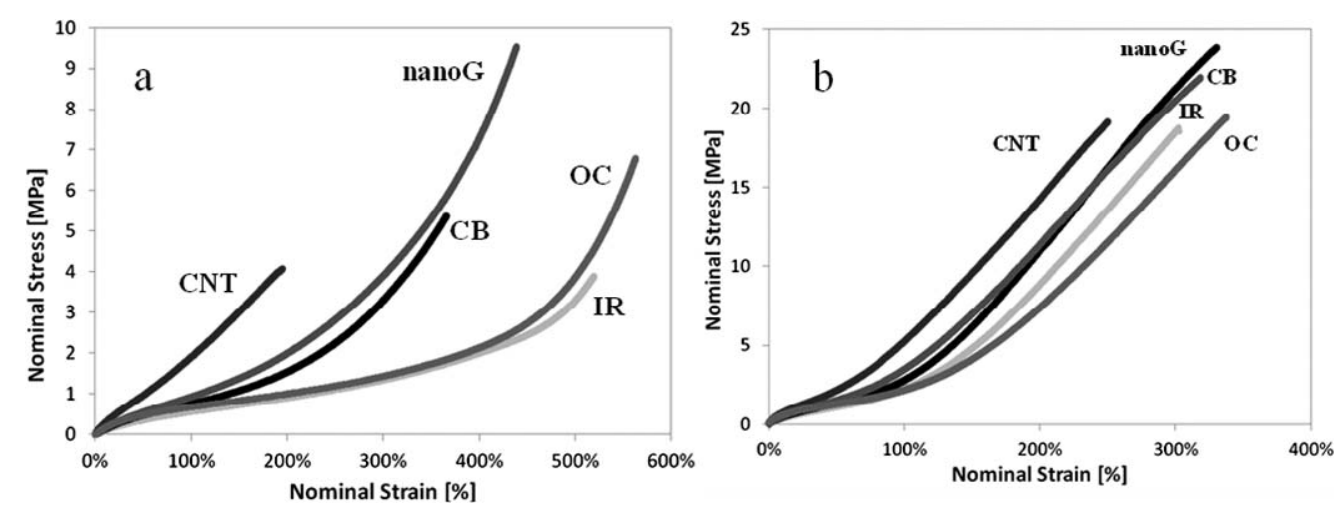

FIG. 20. - Nominal stress versus nominal strain curves for peroxide cross-linked IR-based composites. The matrix is: (a) neat IR or (b) IR $+60 \mathrm{phr}$ of CB. Curves refer to composites without any added filler (IR) or containing 12 phr of either OC, or CNT, or CB.

reinforcement brought about by OC in nanocomposites cross-linked with a sulfur-based system could be due to the increase of the network density due to the interaction of the ammonium cation with sulfur. Vice versa, OC does not give rise to any specific interaction with a cross-linking system such as a peroxide. The prevailing effect on the nanocomposite properties of the lipophilic ammonium cations with long-chain alkenyl substituents is the reduction of the modulus of the matrix, at small and high deformations.

\section{CONCLUSIONS}

The overview of recent advancements reached in our research on RCN prepared via melt blending, demonstrates that nanofillers such as OC, CNT, and nanoG are able to promote substantial improvement of dynamic and quasi-static mechanical properties of rubber composites based on a nanostructured filler such as CB.

The behavior of nanofillers is primarily related to their organization in the polymer matrix. Ultimate dispersion of nanofillers in RCN is achieved through chemical modification, and organic modifiers also play a key role in determining the structure of nanofillers, in particular of layered nanofillers such as OC and nanoG. One of the main characters on the clay scene, the ammonium cation bearing two long hydrocarbon tails, has a great effect on the OC crystalline order, on the OC's ability to delaminate, and on the interaction with CB.

Nanofillers are able to form hybrid filler networks with CB, leading to clear interactive effects on mechanical reinforcement, with enhancement of the initial modulus higher than that expected on the basis of an additive model. Initial modulus values for composites containing CB and/or CNT lie on the same master curve, by correlating them with the polymer-filler interfacial area.

The lower mechanical reinforcement observed for nanoG-based nanocomposites can be attributed to the low accessibility of the nanoG surface to polymer chains, as nanoG tends to form, in the rubber matrix, stacks with tenths of graphene layers.

The mechanical behavior of nanocomposites at medium and high strain reveals the poor interaction of $\mathrm{OC}$ with the polymer matrix in the absence of a sulfur-based cross-linking system.

CNT appear to be the most interesting nanofillers, as they promote the mechanical reinforcement of rubber matrices in the absence and in the presence of a nanostructured filler such as $\mathrm{CB}$, at low and high deformations, independently of the cross-linking system. 


\section{REFERENCES}

${ }^{1}$ M. Maiti, M. Bhattacharya, and A. K. Bhowmick, RubBer CHEM. TeChnol. 81, 384 (2008).

${ }^{2}$ M. Galimberti, V. Cipolletti, and V. Kumar, Natural Rubber Based Composites and Nanocomposites, S. Thomas, C. H. Chan, L. A. Pothan, J. Joy, and H. Maria, Eds., Royal Society of Chemistry, London, 2013.

${ }^{3}$ Vocabulary - Nanoparticles, PAS 71, 2005 BSI.

${ }^{4}$ S. S. Ray and M. Okamoto, Prog. Polym. Sci. 28, 1539 (2003).

${ }^{5}$ B. Chen, J. R. G. Evans, H. C. Greenwell, P. Boulet, P. V. Coveney, A. A. Bowden, and A. Whiting, Chem. Soc. Rev. 37, 568 (2008).

${ }^{6}$ D. R. Paul and L. M. Robeson, Polym. Nanotech. Nanocomp. Polym. 49, 3187 (2008).

${ }^{7}$ M. Galimberti, Rubber Clay Nanocomposites: Science, Technology, Applications, John Wiley and Sons, New York, 2011.

${ }^{8}$ M. Galimberti, Advanced Elastomers: Technology, Properties and Applications, A. Boczkowska, Ed., InTech, Rijeka, Croatia, 2012, Ch. 4.

${ }^{9}$ M. Galimberti, V. Cipolletti, and M. Coombs, Handbook of Clay Science, 2nd ed., Part B: Techniques and Applications, F. Bergaya and G. Lagaly, Eds., Elsevier, Amsterdam, 2013, Ch. 4.4.

${ }^{10}$ L. Bokobza, Polymer 48, 4907 (2007).

${ }^{11}$ S. Araby, Q. S. Meng, L. Q. Zhang, H. L. Kang, P. Majewski, Y. H. Tang, and J. Ma, Polymer 55, 201 (2014).

${ }^{12}$ H. L. Kang, K. H. Zuo, Z. Wang, L. Q. Zhang, L. Liu, and B. C. Guo, Composites Science and Technology 92, 1 (2014).

${ }^{13}$ Y. Y. Mao, S. P. Wen, Y. L. Chen, F. Z. Zhang, P. Panine, T. W. Chan, L. Q. Zhang, Y. R. Liang, and L. Liu, Scientific Reports 3, 2508 (2013).

${ }^{14}$ M. Galimberti, V. Kumar, M. Coombs, V. Cipolletti, S. Agnelli, S. Pandini, and L. Conzatti, RubBER CHEM. TECHNOL., 87, 197 (2014).

${ }^{15}$ N. Yan, H. S. Xia, J. K. Wu, Y. H. Zhan, G. X. Fei, and C. Chen, J. Appl. Polym. Sci. 127, 933 (2013).

${ }^{16}$ C. P. Li, C. F. Feng, Z. Peng, W. Gong, and L. X. Kong, Polym. Comp. 34, 88 (2013).

${ }^{17}$ J. R. Potts, O. Shankar, S. Murali, L. Du, and R. S. Ruoff, Composites Science and Technology 74, 166 (2013).

${ }^{18}$ J. R. Potts, O. Shankar, L. Du, and R. S. Ruoff, Macromolecules 45, 6045 (2012).

${ }^{19}$ F. R. Al-Solamy, A. A. Al-Ghamdi, and W. E. Mahmoud, Polym. Adv. Technol. 23, 478 (2012).

${ }^{20}$ A. Malas, C. K. Das, A. Das, and G. Heinrich, Materials and Design 39, 410 (2012).

${ }^{21}$ L. L. Wang, L. Q. Zhang, and M. Tian, Materials and Design 39, 450 (2012).

${ }^{22}$ L. L. Wang, L. Q. Zhang, and M. Tian, Wear 276, 85 (2012).

${ }^{23}$ M. Hernández, M. D. Bernal, R. Verdejo, T. A. Ezquerra, and M. A. Lopez-Manchado, Composites Science and Technology 73, 40 (2012).

${ }^{24}$ A. K. Bhowmick, M. Bhattacharya, and S. Mitra, J. Elastom. Plast. 42, 517 (2010).

${ }^{25}$ M. Bhattacharya, M. Maiti, and A. K. Bhowmick, Polym. Eng. Sci. 49, 81 (2009).

${ }^{26}$ V. Sridhar, X. Xu, T. T. Pham, S. P. Mahapatra, and J. K. Kim, Polym. Comp. 30, 334 (2009).

${ }^{27}$ M. Mauro, V. Cipolletti, M. Galimberti, P. Longo, and G. Guerra, J. Phys. Chem. C 116, 24809 (2012).

${ }^{28}$ M. Galimberti, V. Cipolletti, M. Coombs, V. Kumar, M. Mauro, G. Guerra, L. Conzatti, and L. Giannini, Proceedings of the Fall 182nd Technical Meeting of the Rubber Division, ACS, Cincinnati, October 9-11, 2012.

${ }^{29}$ V. Cipolletti, M. Galimberti, M. Mauro, and G. Guerra, Appl. Clay Sci., 87, 179 (2014).

${ }^{30}$ F. Bergaya and G. Lagaly, Handbook of Clay Science, 2nd ed., Elsevier, Amsterdam, 2013.

${ }^{31}$ G. Lagaly, M. Ogawa, and I. Dekany, Handbook of Clay Science, 2nd Ed. Part A: Fundamentals, F. Bergaya and G. Lagaly, Eds., Elsevier, Amsterdam, 2013, Ch. 10.3.

${ }^{32}$ M. Galimberti, S. Giudice, V. Cipolletti, and G. Guerra, Polym. Adv. Technol. 21, 679 (2010).

${ }^{33}$ M. Galimberti, V. Cipolletti, and S. Giudice, Rubber Clay Nanocomposites: Science, Technology, Applications, M. Galimberti, Ed., Wiley and Sons, New York, 2011, Ch. 7. 
${ }^{34}$ H. X. Jiang, Q. Q. Ni, and T. Natsuki, Polym. Compos. 32, 236 (2011).

${ }^{35}$ M. Galimberti, S. Senatore, L. Conzatti, G. Costa, G. Giuliano, and G. Guerra, Polym. Adv. Technol. 20, 135 (2009).

${ }^{36}$ M. Galimberti, A. Lostritto, A. Spatola, and G. Guerra, Chem. Mater. 19, 2495 (2007).

${ }^{37}$ S. Rooj, A. Das, K. W. Stöckelhuber, N. Mukhopadhyay, A. R. Bhattacharyya, D. Jehnichen, and G. Heinrich, Appl. Clay Sci. 67-68, 50 (2012).

${ }^{38}$ S. Rooj, A. Das, K. W. Stöckelhuber, D. Y. Wang, V. Galiatsatos, and G. Heinrich, Soft Matter 9, 3798 (2013).

${ }^{39}$ D. Fu, Y. Liu, Y. Su, G. Liu, and D. Wang, J. Phys. Chem. B 115, 4632 (2011).

${ }^{40}$ S. Y. Chazhengina, E. N. Kotelnikova, I. V. Filippova, and S. K. Filatov, J. Mol. Struct. 647, 243 (2003).

${ }^{41}$ G. Ungar, N. Mašić, J. Phys. Chem. 89, 1036 (1985).

${ }^{42}$ T. Itoh, N. Ohta, T. Shichi, T. Yui, and K. Takagi, Langmuir 19, 9120 (2003).

${ }^{43}$ M. Mauro, M. Maggio, V. Cipolletti, M. Galimberti, P. Longo, and G. Guerra, Carbon 61, 395 (2013).

${ }^{44}$ M. Galimberti, V. Cipolletti, M. Mauro, and L. Conzatti, Macromol. Chem. Phys. 214, 17 (2013).

${ }^{45}$ M. Galimberti, M. Coombs, V. Cipolletti, A. Spatola, G. Guerra, A. Lostritto, L. Giannini, S. Pandini, and T. Riccò, Appl. Clay Sci., 97-98, 8 (2014).

${ }^{46}$ F. Schon and W. Gronski, Kaut. Gummi Kunstst. 56, 166 (2003).

${ }^{47}$ G. Ramorino, F. Bignotti, S. Pandini, and T. Riccò, Compos. Sci. Technol. 69, 1206 (2009).

${ }^{48}$ M. Galimberti, M. Coombs, V. Cipolletti, P. Riccio, T. Riccò, S. Pandini, and L. Conzatti, Appl. Clay Sci. 65-66, 57 (2012).

${ }^{49}$ M. Galimberti, M. Coombs, P. Riccio, T. Riccò, S. Passera, S. Pandini, L. Conzatti, A. Ravasio, and I. Tritto, Macromol. Mater. Eng. 298, 241 (2012).

${ }^{50}$ S. Agnelli, V. Cipolletti, S. Musto, M. Coombs, L. Conzatti, S. Pandini, T. Riccò, and M. Galimberti, eXPRESS Polymer Lett. 8, 436 (2014).

${ }^{51}$ G. Huber and T. A. Vilgis, Kaut. Gummi Kunstst. 52, 102 (1999).

${ }^{52}$ F. Flores, D. Graebling, A. Allal, and C. Guerret-Piécourt, J. Phys. D Appl. Phys. 40, 2911 (2007).

${ }^{53}$ F. Brochard-Wyart and P. de Gennes, Eur. Phys. J. E. 1, 93 (2000).

${ }^{54}$ M. Galimberti, M. Coombs, V. Cipolletti, L. Giannini, and L. Conzatti, Appl. Clay Sci., 83, 449 (2013).

${ }^{55}$ A. R. Klyne, B. D. Simpson, and M. L. Studebaker, RubBer ChEM. TeChnOL. 46, 192 (1972).

${ }^{56}$ S. S. Sternstein, G. Ramorino, B. Jang, and A. J. Zhu, RubBER CHEM. TeCHNOL. 78, 258 (2005).

${ }^{57}$ A. R. Payne, Reinforcement of Elastomers, G. Kraus, Ed., Interscience Publishers, New York, 1965, Ch. 3.

[Presented at the Fall 184nd Technical Meeting of the Rubber Division, ACS (Cleveland, OH), 8-10 October 2013]

[Received December 2013, Revised May 2014] 